OPEN ACCESS

Edited by:

Elodie Segura,

Institut Curie, France

Reviewed by:

Onur Boyman,

University of Zurich,

Switzerland

Frederick Masson

INSERM U1043 Centre

de Physiopathologie de Toulouse

Purpan, France

*Correspondence:

Chae Gyu Park

ChaeGyu@yuhs.ac;

ChaeGyu@gmail.com

${ }^{t}$ These authors have contributed equally to this work

Specialty section:

This article was submitted to Antigen Presenting Cell Biology,

a section of the journal

Frontiers in Immunology

Received: 31 December 2020

Accepted: 29 April 2021

Published: 17 May 2021

Citation:

Sohn M, Na HY, Shin HS, Ryu SH,

Park S, In H, Choi W, Park JS,

Hwang S, Chu MK and Park CG (2021) Global Gene Expression of $T$

Cells is Differentially Regulated by Peritoneal Dendritic Cell Subsets in an

IL-2 Dependent Manner.

Front. Immunol. 12:648348. doi: 10.3389/fimmu.2021.648348

\section{Global Gene Expression of T Cells Is Differentially Regulated by Peritoneal Dendritic Cell Subsets in an IL-2 Dependent Manner}

\author{
Moah Sohn $n^{1,2 \dagger}$, Hye Young $\mathrm{Na}^{1,3 \dagger}$, Hyun Soo Shin ${ }^{1,2}$, Seul Hye Ryu ${ }^{1,2}$, Sejung Park ${ }^{1,2}$, \\ Hyunju In ${ }^{1,2}$, Wanho Choi ${ }^{1,2}$, Ji Soo Park ${ }^{1,2}$, Soomin Hwang ${ }^{1,2}$, Min Kyung Chu ${ }^{3}$ \\ and Chae Gyu Park ${ }^{1,2,4,5 *}$

\footnotetext{
${ }^{1}$ Laboratory of Immunology, Severance Biomedical Science Institute, Yonsei University College of Medicine, Seoul, South Korea, ${ }^{2}$ Brain Korea 21 FOUR Project for Medical Science, Yonsei University College of Medicine, Seoul, South Korea, ${ }^{3}$ Department of Neurology, Severance Hospital, Yonsei University College of Medicine, Seoul, South Korea, ${ }^{4}$ Therapeutic Antibody Research Center, GENUV Inc., Seoul, South Korea, ${ }^{5}$ Institute for Immunology and Immunological Diseases, Yonsei University College of Medicine, Seoul, South Korea
}

Dendritic cells (DCs) in peripheral tissues may have a unique role to regulate innate and adaptive immune responses to antigens that enter the tissues. Peritoneal cavity is the body compartment surrounding various tissues and organs and housing diverse immune cells. Here, we investigated the specialized features of classical DC (CDC) subsets following the intraperitoneal injection of a model antigen ovalbumin (OVA). Peritoneal cDC1s were superior to cDC2s in activating OVA-specific CD8 T cells, while both cDCs were similar in stimulating OVA-specific CD4 T cells. Each peritoneal cDC subset differentially regulated the homing properties of CD8 T cells. CD8 T cells stimulated by cDC1s displayed a higher level of lung-homing receptor CCR4, whereas those stimulated by cDC2s prominently expressed various homing receptors including gut-homing molecules CCR9 and $\alpha 4 \beta 7$. Also, we found that CDC1s played a dominating role over cDC2s in controlling the overall gene expression of CD8 T cells. Soluble factor(s) emanating from CD8 $T$ cells stimulated by peritoneal cDC1s were responsible for mediating this dominance of cDC1s, and we identified IL-2 as a soluble factor regulating the global gene expression of $T$ cells. Collectively, our study indicates that different peritoneal cDC subsets effectively diversify $T$ cell responses by altering the level of cytokines, such as IL-2, in the milieu.

Keywords: antigen presentation, dendritic cell, interleukin-2, peritoneal cavity, T cell - DC interactions

\footnotetext{
Abbreviations: Ags, antigens; APCs, antigen presenting cells; cDC, classical dendritic cells; DCs, dendritic cells; DEGs, differentially expressed genes; GSEA, gene set enrichment analysis; IEC, intestinal epithelial cell; i.p., intraperitoneal; i.v., intravenous; Lin, lineage; LPL, lamina propria lymphocytes; LPS, lipopolysaccharide; medLNs, mediastinal lymph nodes; mesLNs, mesenteric lymph nodes; OVA, ovalbumin; PBS, phosphate buffered saline; PCA, principal component analysis; RBCs, red blood cells; Tc, CD8 cytotoxic T cell.
} 


\section{INTRODUCTION}

Dendritic cells (DCs) are professional antigen-presenting cells (APCs) that orchestrate innate and adaptive immune responses $(1,2)$. DCs are a heterogeneous group of cells with various subsets that are differentiated by their ontogeny, localization, and immunological functions (3). DCs can be divided into 3 major subsets, i.e., classical DCs (cDCs) processing and presenting antigens (Ags) in the steady state, monocyte-derived DCs developing and functioning under inflammatory conditions, and plasmacytoid DCs producing type I interferon to facilitate anti-viral immune responses. Again, $\mathrm{cDCs}$ are further divided into at least 2 main subsets, $\mathrm{CDC} 1 \mathrm{~s}$ and $\mathrm{CDC} 2 \mathrm{~s}$. $\mathrm{CDC} 1 \mathrm{~s}$ are better at cross-presenting Ags to induce CD8 $\mathrm{T}$ cell responses, and cDC2s are efficient at promoting CD4 $\mathrm{T}$ cells to proliferate and differentiate (3). Distinct DC subsets have been further identified in various tissues under different conditions, and are shown to carry out specialized functions (4-10). Meanwhile, recent studies have compared the transcriptomes of DC subsets in various tissues and illustrated the commonalities and differences in their expression of genes across tissues $(11,12)$, which further suggests that DC subsets residing in particular tissues may possess unique abilities and functions in addition to the general features of DCs.

DCs regulate and determine the type of $\mathrm{T}$ cell responses with multiple signals. DCs process Ags and present them to T cells in the form of MHC-bound peptides. The responses of cognate $\mathrm{T}$ cells are further modulated by the interaction of co-stimulatory molecules on the surface of T cells and DCs, and additionally by the cytokine milieu (13). IL-2 is one of the important cytokines that regulate the key aspects of T cell biology (14). IL-2 enhances immunostimulatory responses by promoting $\mathrm{CD} 4 \mathrm{~T}$ helper type 1 and type 2 cells as well as CD8 cytotoxic T (Tc) cells, yet it also contributes to immunosuppressive responses by boosting the development and function of regulatory T cells (14-17). Besides, IL-2 also affects the durability of immune responses. Weak or limited IL-2 signaling is critical in the formation of memory T cells $(18,19)$, whereas strong IL-2 signaling, in combination with inflammatory cytokines, induces the expression of transcription factors T-bet and Blimp-1, which in turn promotes the differentiation of short-lived CD8 Tc cells (20). Therefore, the regulation of IL-2 in the milieu is important in dictating the fate of T cells. Although it is believed that DCs have an important role in modulating various cytokines in the milieu and thus regulating the outcome of $\mathrm{T}$ cell responses (21-23), it has remained poorly understood how and which DC subsets are involved in controlling IL-2 in the milieu.

The peritoneal cavity is a specialized compartment enclosed by the peritoneum that houses multiple tissues and immune cells. Macrophages and B1 cells constitute the majority of peritoneal immune cells, and others such as $\mathrm{T}$ cells, eosinophils, neutrophils, NK cells, and DCs are found in smaller numbers (24). Since the peritoneum is supplied with abundant blood vessels, the peritoneal cavity is being commonly used as a systemic injection route for small laboratory animals. Following the intraperitoneal (i.p.) injection, peritoneal DCs must be responsible for the capture, process, and presentation of Ags to $\mathrm{T}$ cells and thus initiating immune responses; however, studies regarding those aspects of peritoneal DCs have been limited. Although recent studies have characterized the diversity of peritoneal DC subsets, the distinct roles between peritoneal cDC subsets are yet to be investigated in depth (25-27). In the previous study (27), we demonstrated that new subsets of peritoneal DCs and macrophages were identified by differences in their ability to present antigens to and thus stimulate $\mathrm{T}$ cells. Our present study examines and compares the capabilities of peritoneal cDC subsets regarding their ability to control $\mathrm{T}$ cell responses, and we have discovered that peritoneal $\mathrm{CDC} 1 \mathrm{~s}$ have a dominating role in modulating CD8 $\mathrm{T}$ cell responses by upregulating the expression of IL-2.

\section{MATERIALS AND METHODS}

\section{Mice}

C57BL/6J mice were purchased from Orient Bio (Seongnam, Korea) and female mice between 6 and 12 weeks of age were used for the experiments. C57BL/6-Tg(TcraTcrb)1100Mjb/J (OT-1), B6.Cg-Tg(TcraTcrb) 425Cbn/J (OT-2), and B6.SJL-Ptprc ${ }^{\mathrm{a} P e p c^{\mathrm{b}} /}$ BoyJ (CD45.1) mice were obtained from the Jackson Laboratory (Bar Harbor, ME, USA). CD45.1 $1^{+}$OT-1 mice were bred in house. All mice were bred and maintained in specific pathogen-free facilities in accordance with the guidelines approved by the Institutional Animal Care and Use Committees of the Yonsei University College of Medicine.

\section{Tissue Harvest and Cell Preparation}

Peritoneal exudate cells were isolated following the protocols previously described (27). In brief, $5 \mathrm{ml}$ of ice-cold isolation buffer, DPBS containing 3\% fetal bovine serum, was injected into the peritoneal cavity. The peritoneal cavity was then gently massaged to dislodge the attached immune cells and the suspended peritoneal cells were harvested. The collected cell suspension was passed through a $100 \mu \mathrm{m}$ strainer, and the cells were washed twice and used for experiments.

For spleen cell preparation, the spleen was mechanically disrupted with a cell strainer and syringe plunger. Disrupted cells were then washed twice with DPBS to filter fibrous materials through the strainer. Red blood cells (RBCs) were lysed with ACKlysis solution (BioLegend, San Diego, CA, USA) and washed twice with DPBS before use (28).

For lymph node single-cell preparation, lymph nodes were isolated and mechanically disrupted on a $100 \mu \mathrm{m}$ cell strainer with a syringe plunger. Fibrous materials were filtered again with a strainer before use (29).

The isolation method of intestinal cells was modified from protocols previously described (30). In brief, small and large intestines were removed and placed in cold DMEM containing 5\% FBS (Avantor Seradigm, Randor, USA). Mesentery lymph nodes and Peyer's patches were carefully removed. Intestines were opened longitudinally and cut into $5 \mathrm{~cm}$ pieces and fecal content was washed. Washed intestinal tissues were incubated with $1 \mathrm{mM}$ EDTA in DMEM at $37^{\circ} \mathrm{C}$ for 15 minutes stirred at $250 \mathrm{rpm}$. The supernatant containing intestinal epithelial cells (IEC) was collected and used. To isolate the lamina propria 
lymphocytes (LPL), the remaining intestinal tissue was washed in DMEM containing 5\% FBS, minced, resuspended in $20 \mathrm{ml}$ of DMEM containing $1 \mathrm{mg} / \mathrm{ml}$ of collagenase D (Roche, Basel, Switzerland), $500 \mu \mathrm{g} / \mathrm{ml}$ of dispase, $50 \mu \mathrm{g} / \mathrm{ml}$ of DNase (Roche), and $1 \%$ FBS (Avantor Seradigm), and was stirred at $250 \mathrm{rpm}$ for 35 minutes at $37^{\circ} \mathrm{C}$. The tissue suspension was collected and passed through a $100 \mu \mathrm{m}$ cell strainer, and remaining tissue fragments were further disrupted mechanically by rubbing with a syringe plunger. Collected lamina propria cells were washed twice before use.

For lung cell preparation, the pulmonary circulation was perfused with $10 \mathrm{ml}$ of HBSS to remove the intravascular pool of cells. Lungs were separated, minced thoroughly, and incubated for 35 minutes in a digestion media containing $5 \mathrm{mg}$ of collagenase $\mathrm{D}$ (Roche) at $37^{\circ} \mathrm{C}$. In the last 5 minutes, $10 \mathrm{mM}$ EDTA was added to quench the digesting action. Tissue fragments were further disrupted mechanically on $100 \mu \mathrm{m}$ cell strainers by rubbing with a syringe plunger. The tissue suspension passed through strainers was washed with HBSS then RBCs were lysed with ACKlysis solution. Cells were washed twice with HBSS before use (29).

\section{Antibodies and Reagents}

The following reagents were purchased from BioLegend: antiLy6G (1A8), anti-CD3 (17A2), anti-CD19 (6D5), anti-CD115 (AFS98), anti-XCR1 (ZET), anti-CD11c (N418), anti-I-A/I-E (anti-MHC II, M5/114.15.2), anti-CD45.1 (A20), anti-CD45.2 (104), anti-CD4 (GK1.5), anti-CD8a (53-5.8), anti-Vo2 (B20.1), anti-TCR $\beta$ chain (H57-597), anti-CD11b (M1/70), anti-F4/80 (BM8), anti-B220 (RA3-6B2), anti- $\alpha 4 \beta 7$ (DATK32), anti-CCR9 (L053E8), anti-CD69 (H1.2F3), anti-CD25 (anti-IL-2R $\alpha$, PC61, unless indicated otherwise), anti-CCR4 (2G12), anti-CD44 (IM7), anti-IL-2R $\beta$ (TM- $\beta 1$ ), anti-CD49b (pan-NK cells, DX5), recombinant mouse IL-6, recombinant mouse IL-2, anti-IL-2 (JES6-1A12), anti-SIINFEKL peptide bound to mouse $\mathrm{H}-2 \mathrm{~K}^{\mathrm{b}}$ (25-D1.16), anti-CD14 (Sa14-2), anti-CD40 (3/23), anti-CD80 (16-10A1), anti-CD83 (Michel-19), anti-CD86 (GL-1), anti-PDL1 (10F.9G2), anti-PD-L2 (TY25), anti-OX40L (RM134L), anti$\mathrm{H}-2$ (M1/42), and brefeldin A. Affinity purified polyclonal antiIL-2 was purchased from R\&D systems (Minneapolis, MN, USA). LPS and all trans-retinoic acid were purchased from Sigma-Aldrich and human TGF- $\beta 1$ from Peprotech (Rocky Hill, NJ, USA). Cell Trace ${ }^{\mathrm{TM}}$ CFSE cell proliferation kit (Thermo Fisher Scientific, Waltham, MA, USA), Cell Trace ${ }^{\mathrm{TM}}$ Violet cell proliferation kit (Thermo Fisher Scientific), LIVE/ DEAD ${ }^{\circledR}$ fixable dead cell stain kit (Thermo Fisher Scientific) were purchased and used according to the manufacturer's instructions. Grade V OVA was purchased from SigmaAldrich (St. Louis, MO, USA) and Endofit OVA was obtained from InvivoGen (San Diego, CD, USA).

\section{Flow Cytometric Analysis and Intracellular Cytokine Staining}

Cells were isolated as described in the previous section. To block nonspecific staining, isolated single cell suspensions were incubated with the culture supernatant of 2.4G2 (anti-CD16/ 32) monoclonal antibody hybridoma for 20 minutes at $4^{\circ} \mathrm{C}$. Cells were washed with FACS buffer (DPBS containing 2\% of FBS and 2 mM EDTA), then antibodies for cell surface markers and dead cell staining dyes were added and incubated for 20 minutes at $4^{\circ} \mathrm{C}$. After surface staining, cells were washed twice and analyzed or sorted with flow cytometry. For intracellular staining, cells were incubated with brefeldin A for the last 4 hours before being harvested. Cells were processed for surface staining. Then, surface-stained cells were resuspended in Fixation/Permeabilization solution (BioLegend) and intracellular cytokine staining was performed according to the manufacturer's protocol. FACSVerse ${ }^{\mathrm{TM}}$ and LSRFortessa ${ }^{\mathrm{TM}}$ flow cytometers (BD Biosciences, San Jose, CA, USA) were used for analysis and FACSAria ${ }^{\mathrm{TM}}$ II (BD Biosciences) was used for sorting. Flow cytometric data were analyzed with FlowJo sofrware (FlowJo, Ashland, Oregon, USA).

\section{Antigen Presentation}

For cell culture, we used DMC7 medium composed of DMEM containing L-glutamine, high glucose, and pyruvate (HyClone, GE Healthcare Life Sciences, IL, USA) supplemented with 7\% fetal bovine serum (Avantor Seradigm), non-essential amino acids (GE Healthcare Life Sciences), antibiotic-antimycotics (GE Healthcare Life Sciences), and 57.2 $\mu \mathrm{M} \beta$-mercaptoethanol (Sigma-Aldrich) (31).

To isolate APCs, mice were injected intraperitoneally (i.p.) or intravenously (i.v.) with soluble OVA (1.5 mg of Grade V, Sigma-Aldrich, unless indicated otherwise), and an hour later, peritoneal exudate cells or splenocytes were harvested as described above. OVA-laden $\mathrm{cDC}$ subsets were isolated from $\mathrm{MHCII}^{+}$population, following the gating strategy in Figure 1A, excluding cells expressing Lin markers (CD3, CD19, Ly6G, and ICAM2) with the FACSAria ${ }^{\mathrm{TM}}$ II cell sorter and used for further experiments.

For naïve T cell isolation, splenic cells from OT-1 and OT-2 mice were enriched by excluding cells expressing CD11b, CD19, CD25, CD44, CD49b, MHCII, F4/80, B220, and CD4 (for OT-1) or CD8 (for OT-2) using biotinylated antibodies and anti-biotin Dynabeads (ThermoFisher Scientific). Purified $\mathrm{T}$ cells were labeled with $0.5 \mathrm{mM}$ CFSE or CTV (Thermo Fisher Scientific) according to the manufacturer's protocol.

For the antigen presentation assay, CFSE or CTV labeled T cells and OVA-laden peritoneal APCs were co-cultured in each well of a 96-well plate. T cells were plated at 25,000 cells, and OVA-laden APCs were mixed with $\mathrm{T}$ cells at the ratio of 1:10 unless indicated otherwise. The culture volume was $250 \mu \mathrm{l}$. For some experiments, blocking Abs (anti-IL-2R $\alpha$, anti-IL-2R $\beta$, antiIL-2), retinoic acid, or cytokines (IL-2, IL-6, TGF- $\beta$ ) were treated in written doses. Conditioned medium was made up with $60 \%$ of the supernatant from the co-culture of peritoneal $\mathrm{cDC}$ subsets and OT-1 T cells and 40\% of fresh DMC7 medium.

\section{Transwell Assay}

Transwell assays were performed in flat bottom 24-well plates with a pore size of $0.4 \mu \mathrm{m}$ (SPL, Seoul, Republic of Korea). Each well was filled with either a mixture of OT-1 T cells and OVA-laden peritoneal cDC2s, or a mixture of OT-1 T cells and OVA-laden peritoneal $\mathrm{cDC} 1 \mathrm{~s}$ as shown (Figure 2C). Total reaction volume was $350 \mu \mathrm{l}$, and to make cells gather together, 


\section{A}

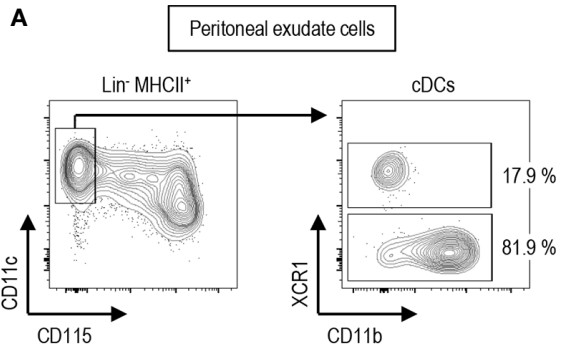

B

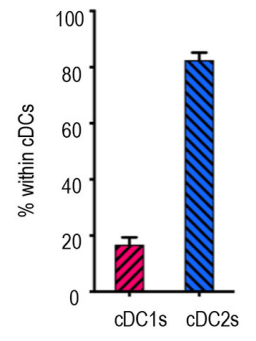

C
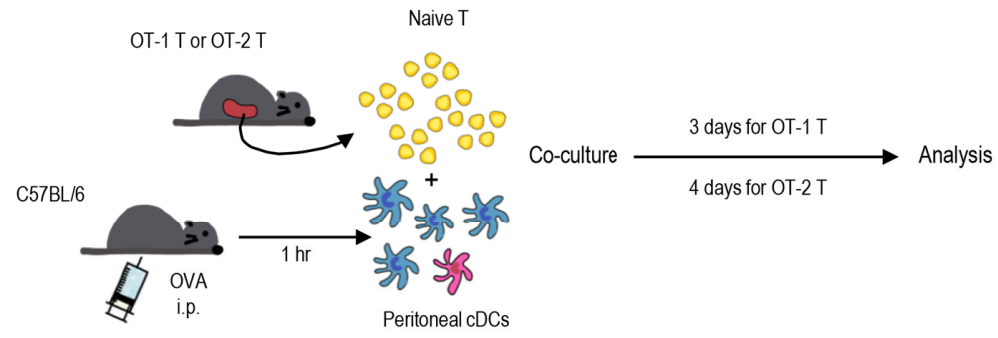

4 days for OT-2 $\mathrm{T}$

D
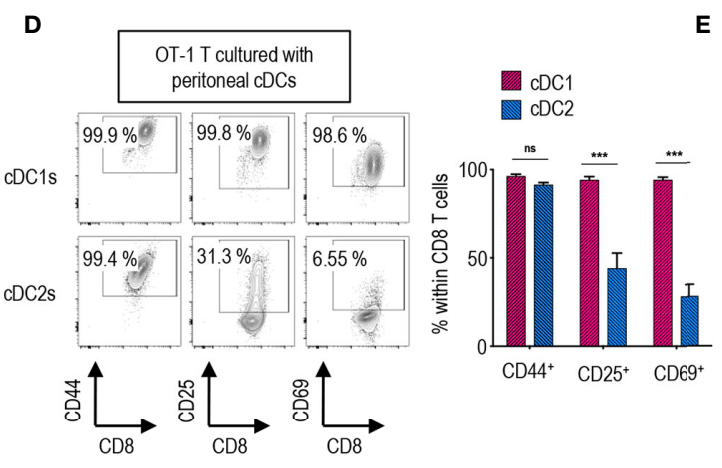

E

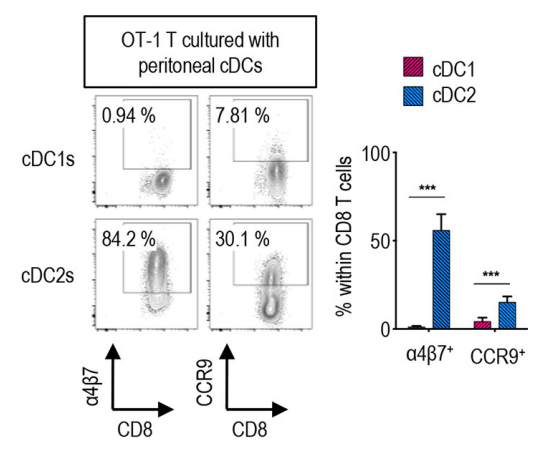

G
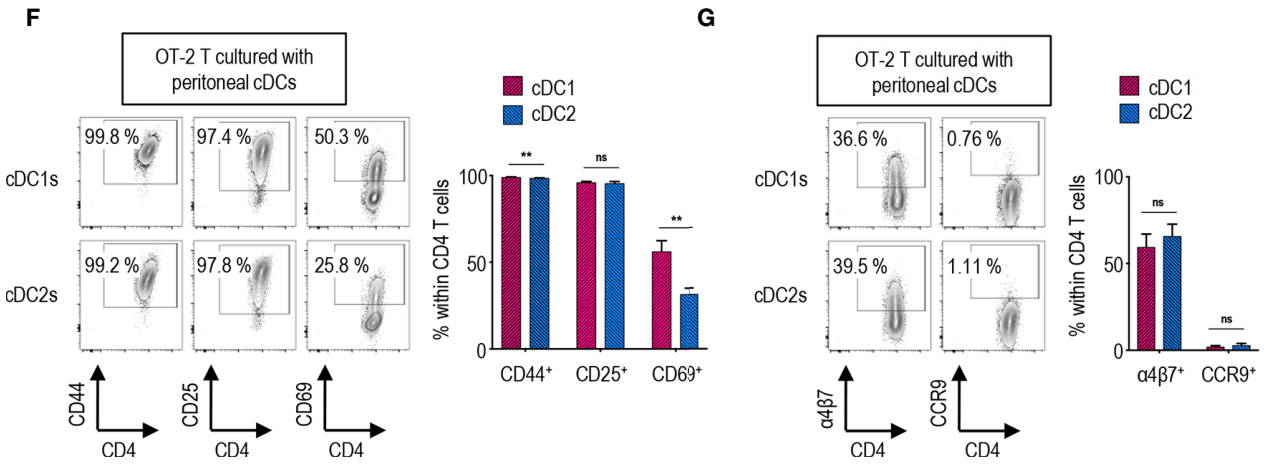

FIGURE 1 | Peritoneal CDC subsets induce distinct T cell responses. (A) Gating strategy of CDC subsets in the peritoneal cavity. Cells expressing Lin markers (CD3, CD19 and Ly6G) were excluded and cDCs were gated from MHCI ${ }^{+}$cells. The percentages of each subset among cDCs are shown (representative of 4 independent experiments). (B) The proportion of $\mathrm{CDC}$ subsets in the peritoneal cavity. The percentages of each subset among CDCs are shown in bar graph. Data are pooled from 4 independent experiments $(n=4)$. Error bars indicate mean \pm SEM. (C) Experimental outline for CD8 (D, E) and CD4 (F, G) T cell responses. 1.5 mg of Ag (OVA, Grade V) was intraperitoneally (i.p.) injected. An hour later, OVA-laden peritoneal cDC subsets were isolated and co-cultured with either naïve OT-1 (CD8 ${ }^{+}$) or OT-2 (CD4 $4^{+}$) T cells in the ratio of 1:10 (APC:T). OT-1 T cells were analyzed on day 3, and OT-2 T cells on day 4. (D-G) CTV proliferated T cells are gated and shown. (D) Activation status of OT-1 T cells stimulated by peritoneal CDC subsets. Expression of CD44, CD25, and CD69 on OT-1 T cells stimulated by peritoneal CDC subsets are shown. (E) Expression of homing molecules, $\alpha 4 \beta 7$ and CCR9, on OT-1 T cells stimulated by peritoneal CDC subsets. (F) Activation status of OT-2 T cells stimulated by peritoneal CDC subsets. Expression of CD44, CD25, and CD69 on OT-2 cells stimulated by peritoneal CDC subsets are shown. (G) Expression of homing molecules, $\alpha 4 \beta 7$, and CCR9 on OT-2 T cells stimulated by peritoneal cDC subsets. Data in graphs are pooled from more than $4 \mathbf{( D ,}, \mathbf{E})$ or $2 \mathbf{( F ,}, \mathbf{G})$ independent experiments $(n \geq 5)$. Error bars indicate mean $\pm S E M$. ${ }^{* *} p<0.01 ;{ }^{* \star *} p<0.001 ; n s$, statistically not significant. 
the plate was tilted during the co-culture. After 3 days of coculture, upper chambers were removed and $\mathrm{T}$ cells from the lower chambers were analyzed.

\section{Antibody Array}

OT-1 T cells and peritoneal cDC subsets were co-cultured for 3 days as described above. The supernatant of each co-culture sample was collected and the expression of 308 proteins were measured using Mouse L308 Array (Ray Biotech, Norcross, GA, USA). The medium from OT-1 T cells cultured without any APCs was also collected and analyzed to exclude the contents included in the culture medium. The antibody array procedures were performed by e-Biogen (Seoul, Republic of Korea). Global normalization was applied using entire spot intensity.

\section{ELISA}

OT-1 T cells and OVA-laden peritoneal cDC subsets were cocultured for 3 days and the supernatant was collected. Then, IL-2 was measured from $100 \mu \mathrm{l}$ of $1 / 10$ diluted supernatant by ELISA following the protocols provided by the manufacturer (BioLegend).

\section{RNA Processing and RNA- Sequencing Analysis}

OT-1 or OT-2 T cells were co-cultured with OVA-laden peritoneal cDC subsets for 3 days as described above. Then, the expanded cells were harvested, and RNA samples were isolated using MiniBEST Universal RNA Extraction kit (TaKaRA Bio, Shiga, Japan). Subsequent mRNA sequencing procedures were performed by Macrogen, Inc (Seoul, Republic of Korea). FPKM values are quantile normalized for comparison. Differential gene expression analysis was performed with ExDega (e-Biogen). Genes with a normalized value of $\leq 1$ in all samples were excluded and only |fold change $\mid \geq 2$ were selected for differentially expressed gene analysis. Pathway analysis was performed using GSEA (Broad Institute). Protein-protein association network was performed with String-DB (http:// string-db.org/). RNA-Sequencing data are available from GEO under accession number GSE150863. RNA-Sequencing data of peritoneal cDC subsets (GEO accession number GSE130424) were generated in our previous publication (27), and here analyzed similarly as above.

\section{Adoptive Cell Transfer and Homing Index Analysis}

OT-1 T cells and peritoneal cDC subsets were co-cultured for 3 days as described above. OT-1 T cells stimulated by $\mathrm{cDC} 2 \mathrm{~s}$ were labeled with CFSE. OT-1 T cells stimulated by either cDC1s or cDC2s with IL-2 (100 ng/ml) were labeled with CTV. 250,000 CFSE-labeled cDC2-stimulated OT-1 T cells were mixed with 250,000 CTV-labeled cDC1-stimulated OT-1 T cells and adoptively transferred i.v. into $\mathrm{C} 57 \mathrm{BL} / 6 \mathrm{~J}$ recipient mice. For OT-1 T cells stimulated with cDC2s and cDC2s with IL-2, 500,000 OT-1 T cells from each stimulation were mixed and adoptively transferred i.v. into C57BL/6J recipient mice. After 3 hours of adoptive transfer, CFSE-labeled vs. CTV-labeled OT-1
T cells were detected from individual tissues, and the respective homing index (HI) was calculated as $\left[\mathrm{CTV}^{+} / \mathrm{CFSE}^{+}\right]_{\text {tissue }} /\left[\mathrm{CTV}^{+} /\right.$ $\left.\mathrm{CFSE}^{+}\right]_{\text {input }}(32)$.

\section{Statistics}

GraphPad Prism 7 and 8 (GraphPad Software, La Jolla, CA) were used for statistical analysis. Statistical comparisons were carried out by using the nonparametric Mann-Whitney tests unless described otherwise. Results are expressed as means \pm sem. $\left.\left.\left.\mathrm{p}<0.05^{*}\right), \mathrm{p}<0.01{ }^{* *}\right), \mathrm{p}<0.001^{(* *}\right)$, and $\left.\mathrm{p}<0.00011^{* * * *}\right)$ were considered to be statistically significant.

\section{RESULTS}

\section{Peritoneal cDC1s and cDC2s Induce a Distinct Expression of Activation and Gut-Homing Markers on CD8 T Cells}

Peritoneal cDCs can be divided into two subsets depending on the expression of surface marker XCR1 (27). cDCs are identified as lineage marker ( $\mathrm{Lin})^{-} \mathrm{CD} 115^{-} \mathrm{CD} 11 \mathrm{c}^{+} \mathrm{MHCII}^{+}$in mouse peritoneal exudate cells (PECs) (Figure 1A). Peritoneal cDCs are composed of $\mathrm{ca} .20 \% \mathrm{XCR}^{+} \mathrm{cDC}^{\mathrm{s}} \mathrm{s}$ and $\mathrm{ca} .80 \% \mathrm{XCR} 1$ cDC2s (Figure 1B). To investigate the differences between peritoneal $\mathrm{cDC} 1 \mathrm{~s}$ and $\mathrm{cDC} 2 \mathrm{~s}$ in regulation of $\mathrm{T}$ cell responses, the expression of activation and gut-homing markers on CD4 and CD8 $\mathrm{T}$ cells were evaluated following stimulation with the respective $\mathrm{cDC}$ subsets. Prior to isolating the $\mathrm{CDC}$ subsets by flow cytometry of PECs, ovalbumin (OVA, grade V, Sigma-Aldrich) was injected i.p. for 1 hour; then, the OVA-laden peritoneal cDC subsets were co-cultured with OVA-specific TCR transgenic $\mathrm{CD}^{+} \mathrm{OT}-1$ or $\mathrm{CD}^{+} \mathrm{OT}-2 \mathrm{~T}$ cells, respectively, in the APC:T ratio of 1:10 (Figure 1C). Both $\mathrm{cDC} 1 \mathrm{~s}$ and $\mathrm{CDC} 2 \mathrm{~s}$ were able to induce the robust proliferation of naïve OT-1 and OT-2 T cells (Supplementary Figures 1, 2A). However, the expression levels of activation markers (Figure 1D and Supplementary Figure 2B) and gut-homing markers (Figure 1E and Supplementary Figure $2 \mathbf{B})$ on the proliferated $\left(\mathrm{CTV}^{\mathrm{lo}}\right) \mathrm{CD}^{+} \mathrm{OT}-1 \mathrm{~T}$ cells were significantly different between the stimulations with $\mathrm{cDC} 1 \mathrm{~s}$ and cDC2s. OT-1 T cells cultured with cDC1s displayed high levels of activation markers, CD25 and CD69, and low levels of guthoming markers, integrin $\alpha 4 \beta 7$ and CCR9, whereas those cultured with $\mathrm{cDC} 2 \mathrm{~s}$ exhibited contrary patterns. Interestingly, on the surface of $\mathrm{CTV}^{\text {lo }} \mathrm{CD}^{+} \mathrm{OT}-2 \mathrm{~T}$ cells, those activation (Figure 1F and Supplementary Figure 2C) and gut-homing markers (Figure 1G and Supplementary Figure 2C) were expressed similarly in response to both $\mathrm{cDC} 1 \mathrm{~s}$ and $\mathrm{cDC} 2 \mathrm{~s}$. We compared the level of $\mathrm{H}-2 \mathrm{~K}^{\mathrm{b}}$ molecules presenting OT-1 peptide on peritoneal $\mathrm{cDC}$ subsets after i.p. treatment with whole OVA protein. Although the difference was small, the fractions of cDC1s expressing OT-1 peptide bound to $\mathrm{H}-2 \mathrm{~K}^{\mathrm{b}}$ on surface were higher than those of cDC2s (Supplementary Figure 3A). In contrast, when OT-1 peptide was injected i.p., the fractions of cDC1s expressing OT-1 peptide bound to $\mathrm{H}-2 \mathrm{~K}^{\mathrm{b}}$ on surface were much lower than those of $\mathrm{cDC} 2 \mathrm{~s}$ (Supplementary Figure 3B). 
A

OT-1 T cultured with peritoneal cDCs
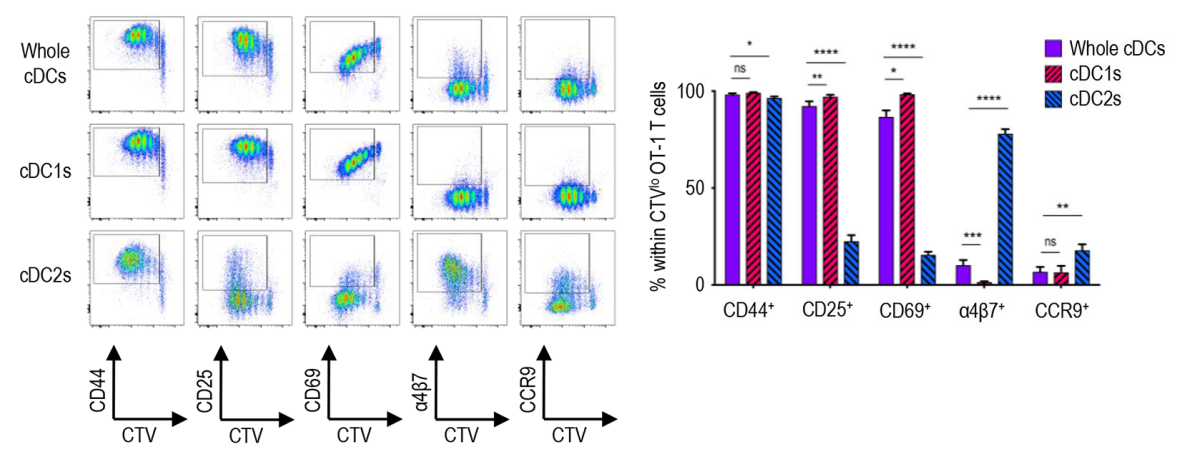

B

OT-1 T cultured with peritoneal $\mathrm{CDC} 2 \mathrm{~s}$ in I = Fresh medium

II = Conditioned medium (OT-1 T with cDC1s)
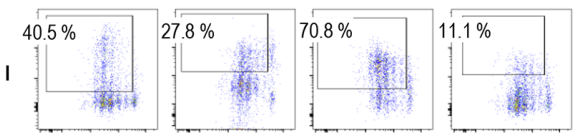

I
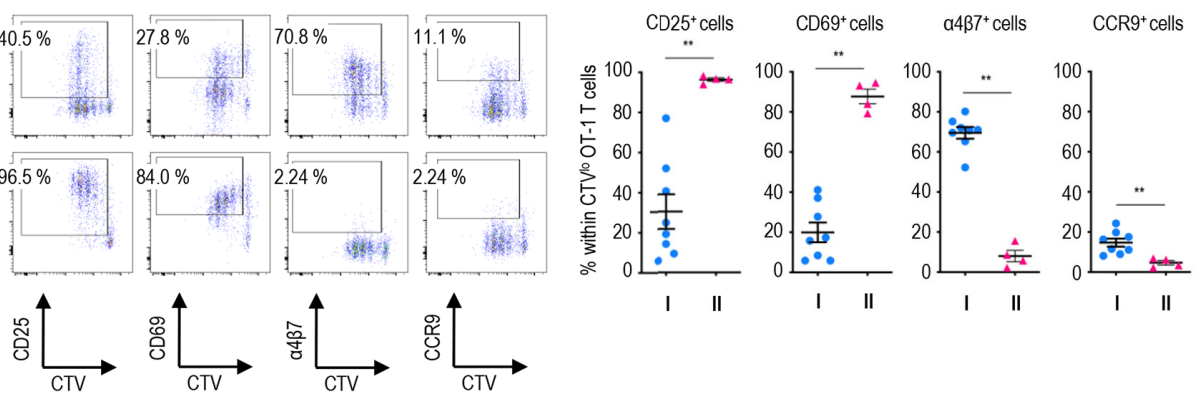

C
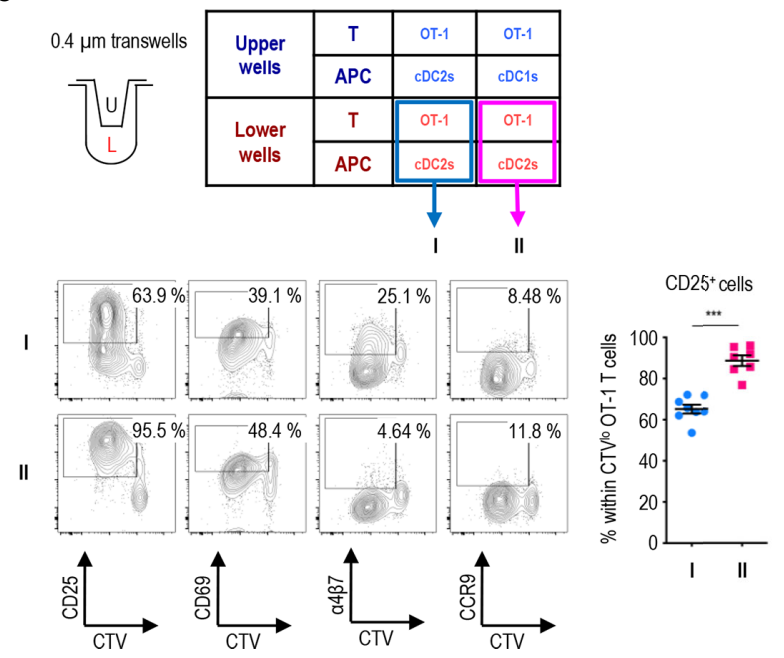

$\mathrm{CD}^{+} 9^{+}$cells

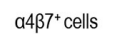

CCR9+cells
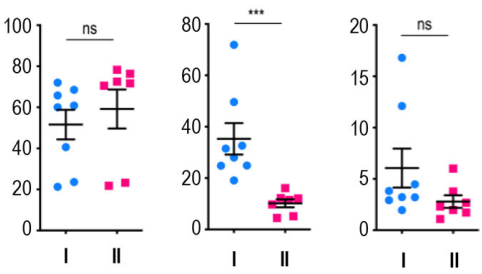

FIGURE 2 | Peritoneal cDC1s play a dominant role in regulating CD8 T cell responses via soluble mediators. An hour after injecting 1.5 mg of OVA (Grade V) i.p., OVA-laden peritoneal cDCs were isolated and co-cultured with naiive OT-1 T cells in the ratio of 1:10 (APC:T). OT-1 T cells were analyzed on day 3. (A) Expression of CD44, CD25, CD69, $\alpha 4 \beta 7$, and CCR9 molecules on OT-1 T cells stimulated by peritoneal whole cDCs and cDC subsets. Live CD8 ${ }^{+}$cells are plotted and the percentages of cells expressing each molecule among CTV ${ }^{\mathrm{lo}}$ proliferated OT-1 T cells are shown in a graph. Data are pooled from 7 independent experiments $(\mathrm{n} \geq 7)$. (B) OT-1 T cells differentiated by peritoneal cDC2s in conditioned medium. Conditioned medium contained fresh complete medium and the supernatant from co-culture of cDC1s and OT-1 T cells in a 2:3 ratio. OVA-laden peritoneal cDC2s and OT-1 T cells were cultured under either fresh complete medium (I, control) or conditioned medium (II). Live CD8 ${ }^{+} \mathrm{T}$ cells are plotted and the percentages of cells expressing each surface molecules are shown in graphs. Data are pooled from 2 independent experiments $(\mathrm{n} \geq 4)$. (C) OT-1 T cells differentiated in $0.4 \mu \mathrm{m}$ pore transwells. OT- $1 \mathrm{~T}$ cells and peritoneal cDCs were co-cultured in transwells for 3 days in combinations as shown in the table. T cells in the lower chamber were analyzed for the expression of CD25, CD69, $\alpha 4 \beta 7$, and CCR9. Live CD8 ${ }^{+} \mathrm{T}$ cells are plotted and the percentages of cells expressing each molecule among CTV ${ }^{\text {lo }}$ proliferated OT-1 T cells are shown in graphs. Data are pooled from more than 2 independent experiments $\left(\mathrm{n} \geq 7\right.$ ). Error bars $(\mathbf{A}-\mathbf{C})$ indicate mean \pm SEM. ${ }^{\star} \mathrm{p}<0.05 ;{ }^{\star \star} \mathrm{p}<0.01$; ${ }^{\star \star \star} \mathrm{p}<0.001 ;{ }^{\star \star \star \star} \mathrm{p}<0.0001$; $\mathrm{ns}$, statistically not significant. 
These results confirm that peritoneal $\mathrm{cDC} 1 \mathrm{~s}$ are better at crosspresenting whole protein than peritoneal $\mathrm{cDC} 2 \mathrm{~s}$. In addition, both OT-1 T cells stimulated by peritoneal cDC1s or cDC2s pulsed i.p. with OT-1 peptide exhibited the phenotype of OT-1 T cells stimulated by cDC2s pulsed i.p. with OVA protein (Supplementary Figure 4). These results suggest that, besides the level of antigen peptide on surface, peritoneal $\mathrm{cDC} 1 \mathrm{~s}$ are distinct from $\mathrm{cDC} 2 \mathrm{~s}$ in their antigen-presenting functions. Meanwhile, OT-1 T cells stimulated by OVA-laden splenic cDC1s and $\mathrm{cDC} 2 \mathrm{~s}$ exhibited the expression of surface markers similarly (Supplementary Figure 5) as OT-1 T cells stimulated by peritoneal $\mathrm{cDC} 2 \mathrm{~s}$, also implying that peritoneal $\mathrm{cDC} 1 \mathrm{~s}$ might have distinct functions.

It has been reported that grade $\mathrm{V}$ OVA contains a low but detectable level of endotoxin (ca. $0.25 \mathrm{EU} / \mu \mathrm{g})(33,34)$. Therefore, by injecting endotoxin-free OVA i.p., we examined the role of endotoxin in the differential expression of markers on $\mathrm{CD}^{+} \mathrm{OT}-$ $1 \mathrm{~T}$ cells between the responses to $\mathrm{cDC} 1 \mathrm{~s}$ and $\mathrm{cDC} 2 \mathrm{~s}$. When laden i.p. with endotoxin-free OVA, both peritoneal $\mathrm{cDC} 1 \mathrm{~s}$ and cDC2s stimulated the robust proliferation of OT-1 T cells but did not produce the differential expression of markers thereon (Supplementary Figure 6A). It was evident that the expression patterns of activation and gut-homing markers on OT-1 T cells stimulated by both $\mathrm{CDC}$ subsets laden with endotoxin-free OVA were quite similar to those stimulated by $\mathrm{CDC} 2$ s laden with grade V OVA (i.e., low levels of activation markers and high levels of gut-homing markers). Meanwhile, when $50 \mathrm{ng}$ of lipopolysaccharide (LPS), the equivalent amount of endotoxin in grade $\mathrm{V}$ OVA, was injected i.p. along with endotoxin-free OVA, OT-1 T cells cultured with cDC1s increased the expression of activation markers and decreased the expression of guthoming markers but those cultured with $\mathrm{cDC} 2 \mathrm{~s}$ did not change markedly (Supplementary Figure 6B). These findings suggest that peritoneal $\mathrm{CDC} 1 \mathrm{~s}$ are more sensitive to the treatment with low doses of LPS and thus better at activating OT-1 T cells. We examined the levels of co-stimulatory molecules on peritoneal cDC subsets after i.p. injection of PBS or LPS. The expression of CD86 was much higher on $\mathrm{CDC} 1 \mathrm{~s}$ than on $\mathrm{CDC} 2 \mathrm{~s}$, but other co-stimulatory molecules were expressed higher on CDC2s than on $\mathrm{CDC1}$ s (Supplementary Figure 7A). Also, the expression level of CD86 was prominently upregulated on $\mathrm{CDC} 1 \mathrm{~s}$ following i.p. treatment with LPS (Supplementary Figure 7B). Then, the gene expression profiles of peritoneal cDC subsets were analyzed from the mRNA-sequencing data of peritoneal myeloid mononuclear cells in our previous study (27), which indicates that TLR4 is expressed similarly between peritoneal cDC1s and cDC2s, but the TLR4 signaling molecules are expressed differentially (Supplementary Figures 8A, B). Collectively, we conclude that peritoneal $\mathrm{cDC} 1 \mathrm{~s}$ possess a unique ability to differentially regulate the expression of various markers on $\mathrm{CD}^{+} \mathrm{OT}-1 \mathrm{~T}$ cells in a manner dependent on the presence of endotoxin. Meanwhile, TGF- $\beta$, which regulates the expression of homing receptors such as integrins and CD69 (35), and many of the TGF- $\beta$ signaling molecules are expressed higher in peritoneal $\mathrm{cDC} 2 \mathrm{~s}$ than in $\mathrm{cDC} 1 \mathrm{~s}$ (Supplementary Figure S8C).

\section{Expression of Activation and Gut-Homing Markers on CD8 T Cells Are Dominantly Regulated by Peritoneal CDC1s via Soluble Mediator(s)}

We also compared the expression of activation and gut-homing markers between $\mathrm{CD}^{+}$OT-1 T cells cultured with peritoneal cDC1s, cDC2, and unseparated whole cDCs. To our surprise, the expression patterns induced by whole cDCs, comprising less than $20 \%$ of cDC1s (Figures 1A, B), were quite identical to those induced by cDC1s, but not by cDC2s (Figure 2A). Meanwhile, the expression levels of those markers on $\mathrm{CD} 4^{+} \mathrm{OT}-2 \mathrm{~T}$ cells showed no differences between the stimulations with peritoneal $\mathrm{cDC1} 1 \mathrm{~s}, \mathrm{cDC} 2$, and whole $\mathrm{cDCs}$ (Supplementary Figure 9). Since $\mathrm{cDC} 1 \mathrm{~s}$, the smaller of the two $\mathrm{cDC}$ subsets, seems to dominantly influence the expression of those markers on OT-1 T cells, we scrutinized whether it was involved with soluble mediator(s) emanating from the co-culture of $\mathrm{cDC} 1 \mathrm{~s}$ and OT-1 T cells. To test this, we collected supernatants from the culture of OT-1 T cells with peritoneal $\mathrm{cDC} 1 \mathrm{~s}$ or $\mathrm{cDC} 2 \mathrm{~s}$, and used the conditioned medium containing each supernatant to culture OT-1 T cells with a respective subset of $\mathrm{cDCs}$. When the conditioned medium from the culture of OT-1 T cells with $\mathrm{CDC} 1 \mathrm{~s}$ was used, the expression patterns of markers on OT-1 T cells stimulated by cDC2s became similar to those stimulated by cDC1s (Figure 2B). However, the conditioned medium from the culture of OT-1 T cells with cDC2s did not affect the expression of markers on OT$1 \mathrm{~T}$ cells stimulated by $\mathrm{cDC} 1 \mathrm{~s}$ (Supplementary Figure 10). Therefore, cDC1s play a dominant role among whole peritoneal $\mathrm{cDCs}$ in regulating the expression of markers on OT-1 T cells via soluble mediator(s). The effect of soluble mediator(s) was further examined using a $0.4 \mu \mathrm{m}$ transwell coculture system. When co-cultured with OT-1 T cells and cDC1s in the upper well of the transwell, the OT-1 T cells with cDC2s in the lower well exhibited increase in the expression of CD25 and decrease in the expression of $\alpha 4 \beta 7$, as compared to those cocultured with OT-1 T cells and cDC2s in the upper well (Figure 2C). However, the changes of CD69 and CCR9 expression on OT-1 T cells in the lower wells were not significant, suggesting that the soluble mediator(s) emanating from the OT-1 T cells cultured with cDC1s was likely less abundant in the lower well of the transwell assay than in the conditioned medium comprising culture supernatants (Figure 2C).

\section{IL-2 Emanating From CD8 T Cells Regulates T Cell Responses}

To identify the soluble mediator(s) that regulates the gene expression, we compared the cytokine expression profiles between the culture supernatants of $\mathrm{CD}^{+} \mathrm{OT}-1 \mathrm{~T}$ cells stimulated by peritoneal cDC1s, cDC2s, and whole cDCs. After screening with antibody microarray for 308 proteins, 33 proteins were detected 1.2-fold or higher in the supernatants from OT-1 T cells cultured with whole cDCs or cDC1s when compared to those from OT-1 T cells cultured with cDC2s (Table 1). Then, among these 33 proteins, we have purchased 22 commercially available recombinant proteins and evaluated their effect on the 
TABLE 1 | List of proteins differentially secreted by OT-1 T cells cultured with different peritoneal cDCs.

\begin{tabular}{|c|c|c|c|c|c|c|}
\hline Protein & $\begin{array}{l}\text { Whole cDCs } \\
\text { /cDC2s }\end{array}$ & $\begin{array}{l}\text { cDC1s/ } \\
\text { cDC2s }\end{array}$ & $\begin{array}{l}\text { Decreased } \alpha 4 \beta 7 \text { on OT-1 } \\
\quad \text { T with } \mathrm{CDC} 2 \mathrm{~s}\end{array}$ & $\begin{array}{l}\text { Decreased CCR9 on OT-1 } \\
\text { T with CDC2s }\end{array}$ & $\begin{array}{l}\text { Increased CD25 on OT-1 } \\
T \text { with CDC2s }\end{array}$ & $\begin{array}{c}\text { Increased CD69 on OT-1 } \\
\text { T with CDC2s }\end{array}$ \\
\hline Fas Ligand & 1.4 & 1.9 & No & No & No & No \\
\hline MMP-3 & 1.3 & 1.9 & No & No & No & No \\
\hline DAN & 1.3 & 1.7 & No & No & No & No \\
\hline |L-20 & 1.3 & 1.6 & No & No & No & No \\
\hline TGF-b1 & 1.6 & 1.6 & No & No & No & No \\
\hline SCF & 1.3 & 1.5 & No & No & No & No \\
\hline TSLP & 1.6 & 1.5 & No & No & No & No \\
\hline Pentraxin3 & 1.3 & 1.5 & No & Nos & No & No \\
\hline Osteoprotegerin & 1.3 & 1.5 & No & No & No & No \\
\hline Granzyme G & 1.3 & 1.4 & No & Nos & No & No \\
\hline TECK & 1.2 & 1.4 & - & - & - & - \\
\hline TGFb3 & 1.2 & 1.3 & No & No & No & No \\
\hline EG-VEGF & 1.2 & 1.3 & - & - & - & - \\
\hline IFN-g & 1.5 & 1.3 & No & No & No & No \\
\hline TL1A/TNFSF15 & 1.2 & 1.3 & No & No & No & No \\
\hline CCL17 & 1.3 & 1.3 & No & No & No & No \\
\hline IGFBP-3 & 1.2 & 1.3 & No & No & No & No \\
\hline IGFBP-1 & 1.2 & 1.2 & No & Nos & No & No \\
\hline Decorin & 1.3 & 1.2 & - & - & - & - \\
\hline Osteoactivin & 1.6 & 1.2 & - & - & - & - \\
\hline IL-6 & 1.3 & 1.2 & No & No & No & No \\
\hline IL-3 & 1.3 & 1.2 & Yes & Nos & No & No \\
\hline IFN-beta & 1.3 & 1.2 & - & - & - & - \\
\hline $\begin{array}{l}\text { MMP-14/LEM- } \\
2\end{array}$ & 1.3 & 1.2 & - & - & - & - \\
\hline
\end{tabular}

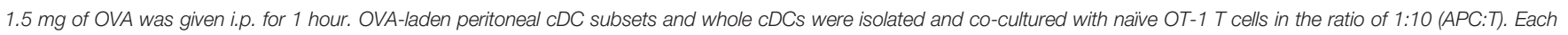

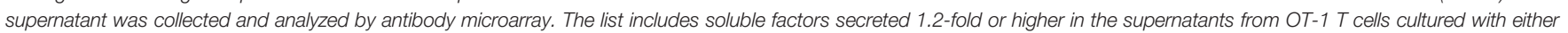
$c D C 1 s$ or whole $c D C$ s, as compared to those cultured with cDC2s. Each protein in the list shows the value of fold change and the result of its influence on OT-1 T cells cultured with cDC2s. $\mathbf{\Delta}$ indicates the increase of CCR9 instead of the decrease.

Change to the indicated phenotype is marked as Yes in bold.

expression of markers on OT-1 T cells cultured with peritoneal cDC2s. The results revealed that only IL-2 was able to modify the expressions of $\alpha 4 \beta 7$, CCR9, CD25, and CD69 (Table 1 and Figure $3 \mathbf{A}$ ), quite as similarly as $\mathrm{cDC} 1 \mathrm{~s}$, whole $\mathrm{cDCs}$, and the conditioned media thereof (Figures 2A, B). Among these 22 tested proteins, other than IL-2, IL-3 could modulate the expression of $\alpha 4 \beta 7$, but not the other markers, on OT-1 T cells. However, no significant change in the expression of markers on OT-1 T cells was observed by blocking the IL-3 signal in the culture with whole cDCs (data not shown).

In a dose-dependent manner, IL-2 was able to up-regulate the expression of activation markers CD25 and CD69, and suppressed the levels of integrin $\alpha 4 \beta 7$ and CCR9 (Figure 3B). We also verified that the expression of IL-2 was prominently elevated in the OT-1 T cells stimulated by peritoneal cDC1s and their culture supernatants (Figures 3C, D). Then, we validated the role of IL-2 by blocking the IL-2 signal in OT-1 T cells cultured with peritoneal $\mathrm{cDC} 1 \mathrm{~s}$. The effect of each individual antibody of anti-IL-2R $\alpha$, anti-IL-2R $\beta$, or anti-IL-2, including JES6-1 known to efficiently inhibit the response of $\mathrm{CD}^{+} \mathrm{T}$ cells to IL-2 in vitro $(14,36)$, was not effective to reverse the phenotype of OT-1 T cells (Supplementary Figure 11). With the combination of anti-IL-2R $\alpha$, anti-IL2R $\beta$, and anti-IL-2, the level of CD69 reduced and the expression of $\alpha 4 \beta 7$ and CCR9 increased significantly (Figure 3E and Supplementary Figure 11). We also confirmed the effect of IL- 2 on CD4 $4^{+}$OT- $2 \mathrm{~T}$ cells cultured with peritoneal $\mathrm{CDC} 2 \mathrm{~s}$ where the addition of IL-2 caused the expression of $\alpha 4 \beta 7$ to decrease and the expression of CD69 to increase significantly (Supplementary Figure 12). Signaling molecules such as retinoic acid, TGF- $\beta$, and IL-6 are known to play an essential role in imprinting gut-homing markers and modulating the activation status of $\mathrm{T}$ cells $(7,37$, 38). We evaluated whether IL-2 could influence the effect of those molecules in OT-1 T cells cultured with peritoneal cDCs. The addition of IL- 6 or TGF- $\beta$ into OT- 1 T cells cultured with whole cDCs down-regulated the expression of CD25 and CD69, and up-regulated the level of $\alpha 4 \beta 7$; besides, IL- 6 down-regulated CD44 expression and TGF- $\beta$ up-regulated CCR9 expression, respectively (Figure 3F). On the other hand, the addition of retinoic acid only up-regulated the expression of CCR9 (Figure 3F). 
However, when IL-2 was included in the cultures, the effects of IL- 6 and TGF- $\beta$ were all reverted but not those of retinoic acid (Figure 3F). In the meantime, the dominant control of IL-2 over the effect of IL- 6 and TGF- $\beta$ was also demonstrated in the culture of OT-1 T cells with peritoneal $\mathrm{cDC} 2 \mathrm{~s}$, where the reverting effect of IL-2 over retinoic acid was limited to the expression of $\alpha 4 \beta 7$ (Supplementary Figure 13). Therefore, IL-2 emanating from OT-1 T cells stimulated by peritoneal $\mathrm{cDC} 1 \mathrm{~s}$ can act in a dominant manner to regulate the expressions of activation and gut-homing markers on T cells.

\section{Peritoneal cDC Subsets Differentially Regulate the Gene Expression Profiles of T Cells}

To further characterize the regulatory role of peritoneal $\mathrm{cDCs}$ over $\mathrm{T}$ cell responses, we performed global mRNA sequencing. $\mathrm{CD}^{+} \mathrm{OT}-1 \mathrm{~T}$ cells were cultured with either whole or individual subsets of OVA-laden peritoneal cDCs in the APC:T ratio of 1:10 for 3 days. OT-1 T cells were also cultured with OVA-laden peritoneal cDC2s in the medium containing IL-2 (cDC2s/IL-2). Then, the gene expression profiles were analyzed and compared between the cells in each co-culture, where almost all cells were expanded $\mathrm{T}$ cells (more than 99\%) but very few were cDCs (less than 1\%). Similarities and differences between the transcriptomes of $\mathrm{T}$ cells cultured with peritoneal $\mathrm{cDCs}$ were analyzed by principal component analysis (PCA) (Figure 4A). The gene expression profiles of OT-1 T cells cultured with $\mathrm{cDC} 1 \mathrm{~s}$ clustered remotely from those cultured with $\mathrm{cDC} 2 \mathrm{~s}$, indicating that the expression of genes in $\mathrm{T}$ cells are differentially regulated by different peritoneal cDC subsets. Meanwhile, the gene expression profiles of OT-1 T cells cultured with peritoneal whole cDCs clustered very closely to those cultured with peritoneal $\mathrm{cDC} 1 \mathrm{~s}$ but apart from those cultured with peritoneal cDC2s, suggesting the superior influence of $\mathrm{cDC} 1 \mathrm{~s}$, compared to cDC2s, over the gene expression of T cells. We also investigated the impact of IL-2 on the gene expression profile of OT-1 T cells cultured with peritoneal cDC2s. In PCA, by the addition of IL-2, OT-1 T cells cultured with peritoneal cDC2s clustered distinctively from those cultured with peritoneal cDC subsets without IL-2 (Figure 4A). It is notable that the first principal component (PC1) distinguishes the OT-1 T cells stimulated by cDC2s with IL-2 from the other clusters of those stimulated by cDC subsets without IL-2. However, the PC2 discriminates the OT- $1 \mathrm{~T}$ cells stimulated by cDC2s with IL-2, clearly from those stimulated by $\mathrm{CDC} 2 \mathrm{~s}$ without IL-2, but not from those stimulated by $\mathrm{CDC} 1$ s or whole $\mathrm{CDC}$ s without IL-2 (Figure 4A). These results indicate that there exist IL-2 dependent and IL-2 independent sets of genes expressed differentially between the OT-1 T cells cultured with $\mathrm{cDC} 1 \mathrm{~s}$ versus cDC2s.

Then, we examined the differentially expressed genes (DEGs) between OT-1 T cells cultured with $\mathrm{cDC} 1$ s versus $\mathrm{CDC} 2 \mathrm{~s}$ (Figure 4B), where 351 genes were up-regulated in the OT-1 T cells cultured with $\mathrm{CDC} 1 \mathrm{~s}$ and 522 genes were up-regulated in those cultured with cDC2s (Figure 4C, upper left diagram). We also compared the DEGs between OT-1 T cells cultured with whole cDCs versus $\mathrm{cDC1}$ s, where only 54 genes were differentially expressed (Figure 4C, upper middle diagram), and those between OT-1 T cells cultured with whole cDCs versus $\mathrm{cDC} 2 \mathrm{~s}$, where 538 genes were differentially regulated (Figure 4C, upper right diagram). Notably, more than $80 \%$ of the 538 DEGs between the OT-1 T cells cultured with whole cDCs versus cDC2s were overlapped with the DEGs between those cultured with $\mathrm{cDC} 1 \mathrm{~s}$ versus $\mathrm{cDC} 2 \mathrm{~s}$ (Figure 4C, lower diagram), also suggesting the dominant role of $\mathrm{cDC} 1 \mathrm{~s}$ in controlling the gene expression of $\mathrm{T}$ cells. We extended the DEG analysis to include the OT-1 T cells stimulated by cDC2s with IL-2. Among the 464 DEGs common to both gene expression profiles of OT-1 T cells stimulated by whole $\mathrm{cDCs}$ and $\mathrm{CDC} 1$ s over those stimulated by cDC2s, 160 genes were overlapped with the DEGs in those stimulated by $\mathrm{cDC} 2 \mathrm{~s}$ with IL-2 over those stimulated by $\mathrm{cDC} 2 \mathrm{~s}$ without IL-2 (Figure 4C, lower diagram). These overlapping genes, such as Il2ra, Itga4, Itgb, and ccr9, were classified as IL-2 responsive DEGs, and non-overlapping genes as IL-2 independent DEGs (Figures $\mathbf{4 C - E}$ ). It is notable that, while the expression of many genes involving $\mathrm{T}$ cell activation and differentiation in OT-1 T cells was distinctively affected by the treatment of IL-2 during stimulation with peritoneal cDC2s, the gene expression of IL-2 and CD62L was not influenced by the treatment of IL-2 (Supplementary Figure 14). Meanwhile, we also analyzed the gene expression profiles of OT-2 T cells stimulated by different subsets of peritoneal cDCs. Unlike CD8 ${ }^{+}$OT-1 T cells, there existed only a few DEGs between $\mathrm{CD}^{+}$OT-2 $\mathrm{T}$ cells cultured with different peritoneal cDCs (Figures 4F, G).

Next, we conducted gene set enrichment analysis (GSEA) to identify pathways and processes associated with the differential responses of OT-1 T cells to different cDC subsets. OT-1 T cells cultured with $\mathrm{cDC} 1 \mathrm{~s}$ were enriched with genes involving the pathways for JAK-STAT signaling and cytokine-cytokine receptor interaction (Figure $\mathbf{4 H}$ ). Meanwhile, those cultured with $\mathrm{cDC} 2 \mathrm{~s}$ were enriched with genes in the pathways involving leukocyte transendothelial migration and actin cytoskeleton regulation (Figure 4I). Because the numbers of genes were not large enough for GSEA, we then analyzed the pathways involved in IL-2 responsive and IL-2 independent DEGs using StringDB and constructed a protein-protein association network. In the IL-2 responsive gene set, we identified that the up-regulated genes were involved in cytokine-cytokine receptor interaction, such as Ifng, Lta, Fasl, Tnf, Ccl3, Ccl4, and Ccr4, whereas the down-regulated genes were involved in leukocyte migration, such as Itgb7, Itga4, Itgae, and S1pr1 (Supplementary Figure 15). In the IL-2 independent gene set, we found that the up-regulated genes were involved in metabolic pathways, such as Cth, Acsl6, Bcat1, Polr1b, Ctps, $A k 4, G l s 2$, and Nos2 (Supplementary Figure 16). In addition, we also looked into gene expression modules related to the functional status of $\mathrm{CD}^{+} \mathrm{T}$ cells (39). OT-1 T cells, stimulated by peritoneal $\mathrm{cDC} 2 \mathrm{~s}$, up-regulated the expression of a considerable number of genes involved in dysfunction but fewer number of genes involved in activation. In contrast, OT$1 \mathrm{~T}$ cells, stimulated by whole $\mathrm{cDCs}, \mathrm{cDC} 1 \mathrm{~s}$, or $\mathrm{cDC} 2 \mathrm{~s}$ with IL-2, induced a significantly greater number of genes involved in 
A

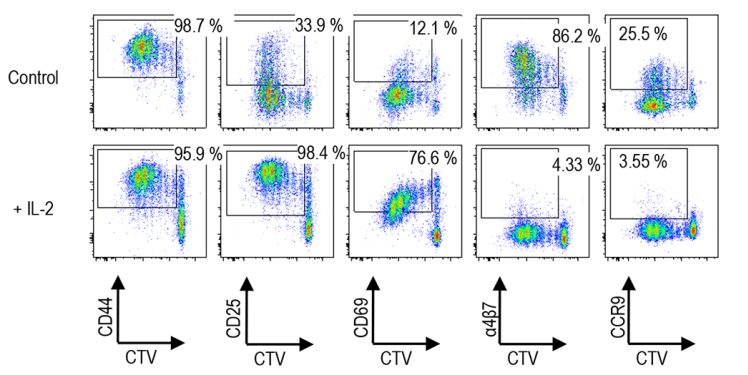

B OT-1 T cultured with peritoneal cDC2s and IL-2

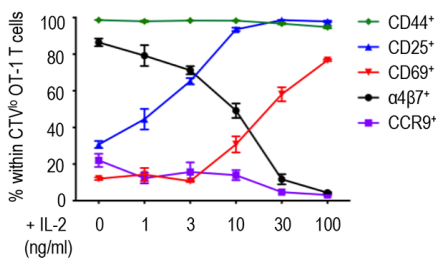

C

OT-1 T cultured with peritoneal cDCs

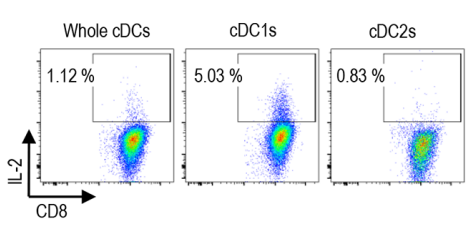

E

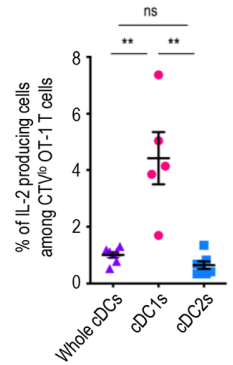

D

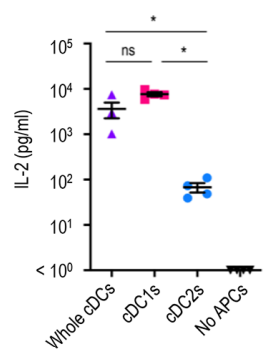

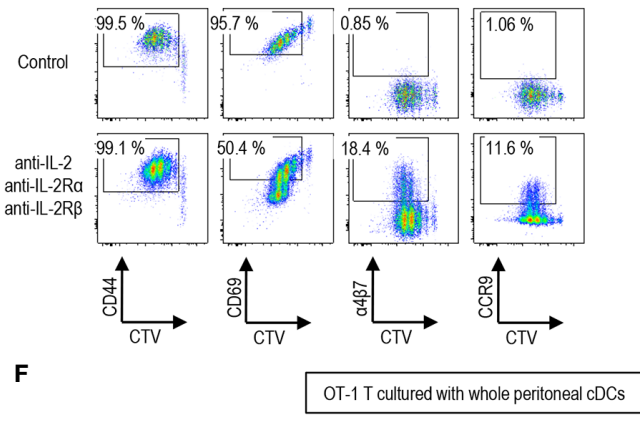

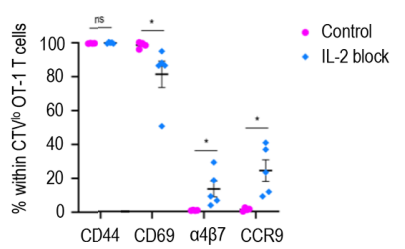

CD44+cells

CD25+cells

CD69+cells

a $4 \beta 7^{+}$cells

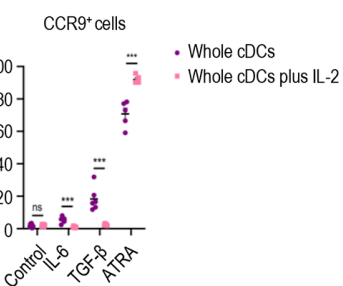

FIGURE 3 | IL-2 produced by CD8 T cells regulates T cell responses. $1.5 \mathrm{mg}$ of OVA (Grade V) was injected into the peritoneal cavity for an hour. OVA-laden peritoneal cDC subsets were sorted and co-cultured with naïve OT-1 T cells for 3 days before analysis. (A) Expression of CD44, CD25, CD69, $\alpha 4 \beta 7$, and CCR9 molecules on OT-1 T cells stimulated by peritoneal cDC2s with or without $100 \mathrm{ng} / \mathrm{ml}$ of IL-2 for 3 days. Live CTV ${ }^{\mathrm{lo}} \mathrm{CD} 8^{+} \mathrm{T}$ cells are plotted and the percentages of cells expressing each molecule among CTV ${ }^{\text {lo }}$ proliferated OT-1 T cells are denoted (representative of more than 5 independent experiments). (B) Effect of graded doses of IL-2 on OT-1 T cells. OT- $1 \mathrm{~T}$ cells were co-cultured with peritoneal cDC2s with the indicated doses of IL-2 for 3 days. The percentages of cells expressing each molecule among CTV ${ }^{l o}$ proliferated OT- 1 T cells are shown in a graph. Data are pooled from more than 3 independent experiments $(n=3)$. (C) Intracellular staining of IL-2. OT-1 T cells were stimulated by peritoneal cDCs for 3 days, and treated with Brefeldin A for the last 4 hours. Live CTV ${ }^{\mathrm{lo}} \mathrm{CD}^{+}$cells are plotted and the percentages of OT-1 T cells expressing IL-2 among CTV ${ }^{\mathrm{lo}}$ proliferated OT-1 cells are shown in a graph. Data are pooled from 2 independent experiments $(n=5)$. (D) IL-2 was measured by ELISA from the supernatant collected from OT-1 T cells stimulated by peritoneal cDCs for 3 days $(n=4)$. (E) Expression of CD44, CD69, $\alpha 4 \beta 7$, and CCR9 molecules on OT-1 T cells stimulated by peritoneal cDC1s while blocking IL-2 signaling. OT-1 T cells and peritoneal cDC1s were co-cultured with antibodies blocking IL-2 signaling (2 $\mu \mathrm{g} / \mathrm{ml}$ of polyclonal anti-IL-2, $10 \mu \mathrm{g} / \mathrm{ml}$ of PC61 anti-IL-2R $\alpha$, and $10 \mu \mathrm{g} / \mathrm{ml}$ of TmB1 anti-IL-2RB) for 3 days. Live CTV ${ }^{\mathrm{lo}} \mathrm{CD} 8^{+} \mathrm{T}$ cells are plotted and the percentages of cells expressing each molecule among CTV ${ }^{\mathrm{lo}}$ proliferated OT-1 T cells are shown in a graph. Data are pooled from 3 independent experiments $(n=5)$. (F) Effect of IL-2 and other immunomodulating molecules. OT-1 T cells and peritoneal whole cDCs were co-cultured with or without $1 \mu \mathrm{g} / \mathrm{ml}$ of IL-2 under specified conditions ( $20 \mathrm{ng} / \mathrm{ml}$ of IL-6, $6 \mathrm{ng} / \mathrm{ml}$ of TGF- $\beta$, or $20 \mu \mathrm{M}$ of ATRA). The percentages of cells expressing each molecule among CTV ${ }^{\circ}$ proliferated OT-1 T cells are shown in graphs. Data are pooled from 2 independent experiments ( $\mathrm{n} \geq 5$ ). Error bars (B-F) indicate mean \pm SEM. ${ }^{*} \mathrm{p}<0.05 ;{ }^{* \star} \mathrm{p}<0.01 ;{ }^{* \star *} \mathrm{p}<0.001 ;{ }^{\star \star \star *} \mathrm{p}<0.0001$; ns, statistically not significant. 
activation than those stimulated by $\mathrm{cDC} 2 \mathrm{~s}$. However, the upregulated genes in OT-1 T cells stimulated by cDC2s with IL-2 were rather different from those in OT-1 T cells stimulated by whole $\mathrm{cDCs}$ and $\mathrm{cDC} 1 \mathrm{~s}$ (Figure 4J). Thus, peritoneal $\mathrm{cDC} 2 \mathrm{~s}$ likely cause the dysfunction of OT-1 T cells, while cDC1s contribute to the activation of OT-1 T cells via controlling the expression of a large number of genes in IL-2 dependent as well as IL-2 independent manners. All in all, our analyses reveal the distinctive features of peritoneal $\mathrm{cDC} 1 \mathrm{~s}$ and $\mathrm{cDC} 2 \mathrm{~s}$ that regulate the gene expression in $\mathrm{CD}^{+} \mathrm{OT}-1 \mathrm{~T}$ cells.

\section{Different Subsets of Peritoneal cDCs Induce Distinct Homing Properties of T Cells}

Since the expression of gut-homing markers, $\alpha 4 \beta 7$ and CCR9, on $\mathrm{CD}^{+} \mathrm{OT}-1 \mathrm{~T}$ cells was differentially regulated between the stimulation with peritoneal $\mathrm{cDC} 1 \mathrm{~s}$ and $\mathrm{CDC} 2 \mathrm{~s}$, we further examined the expression of other integrins and chemokine receptors. Integrins are expressed on cell surfaces as heterodimers formed by $\alpha$ and $\beta$ subunits. An integrin $\alpha 4$ can form heterodimers with either integrin $\beta 1$ or $\beta 7$, while integrin $\beta 7$ can be paired with either integrin $\alpha 4$ or $\alpha$ e (Supplementary Figure 17). In particular, the heterodimers formed with integrin $\beta 7$ play critical roles in gut trafficking of leukocytes (40). Therefore, we examined the expression of individual integrin subunits on OT-1 T cells following stimulation with peritoneal cDCs (Figure 5A and Supplementary Figures 18, 19). In accordance with their expression of $\alpha 4 \beta 7$, both integrin subunits $\alpha 4$ and $\beta 7$ were expressed on OT-1 T cells stimulated by cDC2s. Meanwhile, OT- $1 \mathrm{~T}$ cells stimulated by $\mathrm{cDC} 2 \mathrm{~s}$ with IL-2 sharply down-regulated the expression of integrin $\beta 7$. Similarly, OT-1 T cells stimulated by whole cDCs and $\mathrm{cDC} 1 \mathrm{~s}$ failed to express integrin $\beta 7$ but maintained the expression of integrin $\alpha 4$ on the cell surface. Additional evaluation of integrins $\alpha \mathrm{e}$ and $\beta 1$, the other binding partners of integrins $\beta 7$ and $\alpha 4$ respectively, revealed that $\mathrm{cDC} 2 \mathrm{~s}$ up-regulated both integrins $\alpha \mathrm{e}$ and $\beta 1$ on OT- 1 T cells, whereas whole $\mathrm{cDCs}, \mathrm{cDC} 1 \mathrm{~s}$, and $\mathrm{cDC} 2 \mathrm{~s}$ with IL-2 induced $\beta 1$ but not $\alpha e$ (Figure 5A and Supplementary Figures 18, 19). Collectively, the expression of integrins $\beta 7$ and $\alpha$ e, best known for gut-homing properties, on $\mathrm{CD}^{+} \mathrm{OT}-1 \mathrm{~T}$ cells was sustained by peritoneal cDC2s but suppressed by $\mathrm{cDC} 1 \mathrm{~s}$ or cDC2s with IL-2.

We also examined the influence of peritoneal cDCs on the expression of chemokine receptor genes in OT-1 T cells (Supplementary Figure 20). In addition to CCR9, the stimulation with peritoneal $\mathrm{CDC} 2 \mathrm{~s}$ strongly induced the gene expression of Cxcr3, Cxcr4, Cxcr6, and Xcr1, which are homing receptors to multiple organs including both lymphoid and nonlymphoid tissues $(41,42)$. Peritoneal cDC1s significantly upregulated the gene expression of Ccr4, Ccr6, and Ccr8, known to be important in homing to the lung and the skin $(32,41,42)$. Meanwhile, OT-1 T cells stimulated by cDC2s with IL-2 increased the gene expression of more diverse chemokine receptors, including Ccr2, Ccr3, Ccr4, Ccr5, Ccr10, Cxcr3, Cxcr4, and Cxcr6 (Supplementary Figure 20). Then, we assessed the surface expression of chemokine receptors and confirmed the augmented expression of CCR4 on the surface of OT-1 T cells stimulated by $\mathrm{CDCls}$ as compared to those stimulated by cDC2s (Figure 5B). The low expression of CCR4 on OT-1 T cells stimulated by $\mathrm{cDC} 2 \mathrm{~s}$ was influenced by treatment of the conditioned medium from the culture of OT$1 \mathrm{~T}$ cells with $\mathrm{CDC1s}$ (Supplementary Figure 21). We then demonstrated that the addition of IL-2 to the culture with cDC2s significantly up-regulated the expression of CCR4 on OT-1 T cells (Figure 5C), and that the inhibition of IL-2 signaling significantly reduced the expression of CCR 4 on OT-1 T cells cultured with cDC1s (Figure 5D). Therefore, the level of CCR4 on $\mathrm{CD}^{+} \mathrm{OT}-1 \mathrm{~T}$ cells are up-regulated by the stimulation with peritoneal $\mathrm{cDC} 1 \mathrm{~s}$ in an IL-2 dependent manner. Meanwhile, the expression of TGF- $\beta$ and TGF- $\beta$ signaling molecules, which regulate the expression of homing receptors (35), in OT-1 T cells is not markedly affected by the stimulation with different peritoneal cDC subsets and IL-2 (Supplementary Figure 22).

To determine whether OT-1 T cells stimulated by different peritoneal $\mathrm{cDC}$ subsets possess distinct properties to migrate into peripheral tissues in vivo, we examined their homing capacities using competitive adoptive transfer experiments (32). OT-1 T cells stimulated and expanded by 2 different peritoneal cDC subsets were labeled respectively with 2 different fluorescent dyes (i.e., CFSE and CTV), mixed in an equal ratio, and then adoptively transferred intravenously into recipient mice. At 3 hours following adoptive transfer, various lymphoid and peripheral tissues were harvested and analyzed for the presence of fluorescently labeled OT-1 T cells. The HI (the ratio of $\left[\mathrm{CTV}^{+}\right.$ cells/CFSE ${ }^{+}$cells] in tissue to $\left[\mathrm{CTV}^{+}\right.$cells/CFSE ${ }^{+}$cells] in input) indicated that OT-1 T cells stimulated by $\mathrm{cDC} 2 \mathrm{~s}$ were able to traffic to various tissues, including the mediastinal lymph nodes (medLNs), mesenteric lymph nodes (mesLNs), spleen, and lungs, while those stimulated by $\mathrm{cDC} 1 \mathrm{~s}$ migrated preferentially to the lung but poorly to the lymphoid tissues (Figure 5E, upper panels). When the migration of OT-1 T cells was compared between the cultures with $\mathrm{cDC} 2 \mathrm{~s}$ versus $\mathrm{cDC} 2 \mathrm{~s}$ with IL-2, both groups of OT-1 $\mathrm{T}$ cells were able to migrate to various tissues (Figure 5E, lower panels). It was notable that none of the adoptively transferred OT$1 \mathrm{~T}$ cells were detected in exudates from the peritoneal cavity (Figure 5E). In addition, despite the significantly elevated levels of gut-homing molecules on OT-1 T cells stimulated by cDC2s, none of those were detectable in the gut tissues (Supplementary Figure 23). These results suggest that OT-1 T cells stimulated by $\mathrm{cDC} 1 \mathrm{~s}$ express lung-homing molecules, such as CCR4, as the dominant homing mechanism, whereas those stimulated by $\mathrm{cDC} 2 \mathrm{~s}$ support broad homing properties.

\section{DISCUSSION}

Upon stimulation with APCs, T cells undergo several changes. T cells become activated, differentiate into specific subsets, and alter their tissue-specific homing molecules (41, 43, 44). We evaluated these features of $\mathrm{T}$ cells stimulated by peritoneal $\mathrm{CDC}$ subsets and found that different $\mathrm{cDC}$ subsets made differences in the expression of activation and homing receptors on $\mathrm{CD}^{+} \mathrm{OT}-1$ 


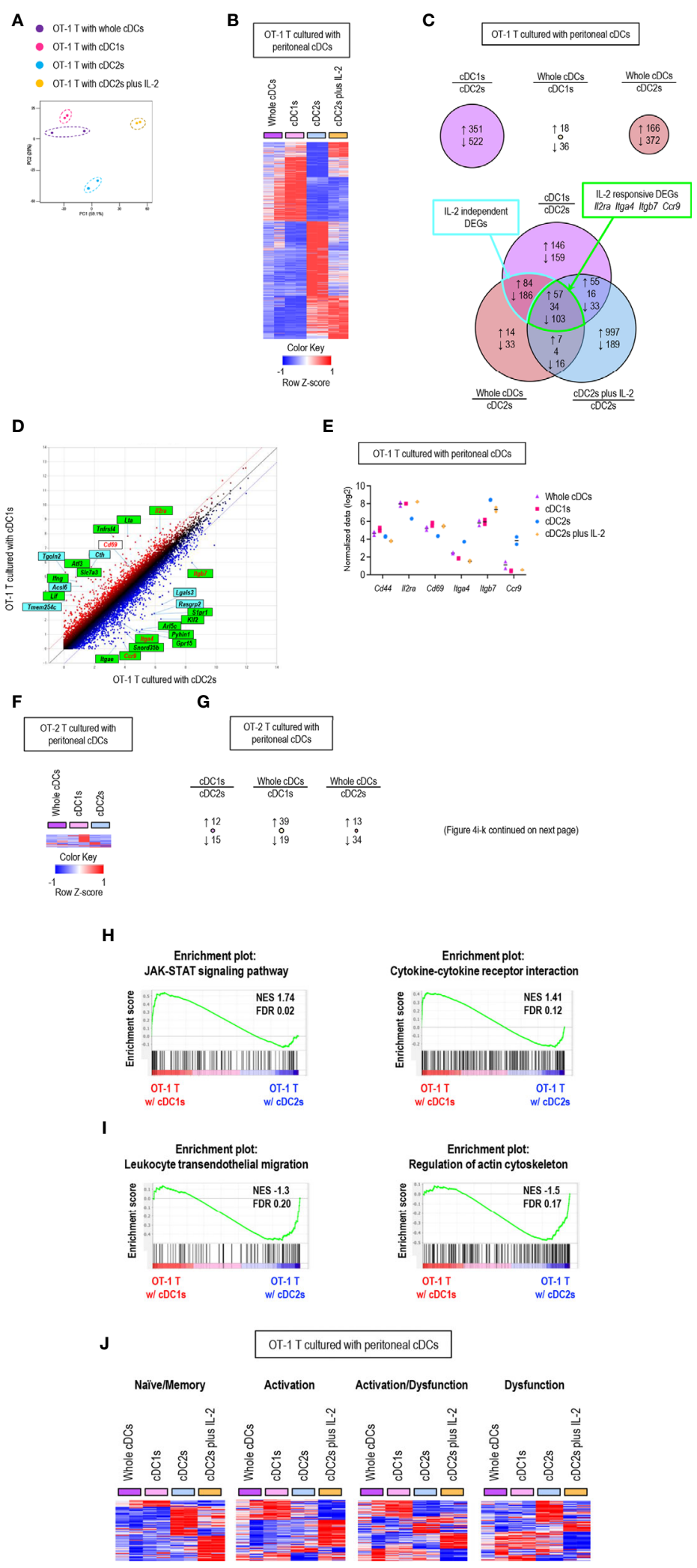

FIGURE 4 | Continued 


\begin{abstract}
FIGURE 4 | Gene expression profiles of T cells are differentially regulated by peritoneal cDC subsets. 1.5 mg of OVA (Grade V) was injected into the peritoneal cavity for an hour. OVA-laden peritoneal cDC subsets were isolated and co-cultured with either naïve OT-1 or OT-2 T cells for 3 days before performing mRNA-sequencing for the transcriptional profiling analyses. Transcriptional profiling analyses were also performed for OT-1 T cells co-cultured with OVA-laden peritoneal cDC2s in 100 $\mathrm{ng} / \mathrm{ml}$ of IL-2 for 3 days. (A) PCA analysis of OT-1 T cells stimulated by peritoneal cDCs. (B) Heatmap of the 873 differentially expressed genes (log2 fold change $>1$ ) between OT-1 T cells stimulated by peritoneal CDC1s and cDC2s. Two replicates per subset are shown. Color scale depicts z-score. (C) Venn diagram shows the overlap between genes with fold change $>2$ in OT-1 T cells stimulated by peritoneal cDCs. Number of genes that are increased (up-arrow, red), decreased (downarrow, blue), or contra regulated (no-arrow, black) are shown. (D) Scatter plot of log intensity comparing gene expression between OT-1 T cells stimulated by peritoneal cDC1s and cDC2s. Top 10 genes differentially expressed (black) and II2ra, Cd69, Itga4, Itgb7, and Ccr9 (red) are shown. The genes within green boxes are IL-2 responsive and blue boxes are IL-2 independent. (E) Expression (normalized value, log2) of Cd44, II2ra, Cd69, Itga4, Itgb7, and Ccr9 in OT-1 T cells stimulated by peritoneal cDCs $(n=2)$. (F) Heatmap of the 58 differentially expressed genes (log2 fold change $>1$ ) between OT-2 T cells stimulated by peritoneal cDC1s and cDC2s. Two replicates per subset are shown. Color scale depicts z-score. (G) Number of differentially expressed genes (log2 fold change $>1$ ) that are increased (up-arrow, red), or decreased (down-arrow, blue) in OT-2 T cells stimulated by peritoneal cDCs are shown. (H, I) Enriched pathway analysis using the C7 GSEA collection (ImmunoSigDB). (H) Representative enrichment plot from OT-1 T cells stimulated by peritoneal cDC1s compared to cDC2s,

"JAK_STAT_signaling_pathway" and "Cytokine_cytokine_receptor_interaction". (I) Representative enrichment plot from OT-1 T cells stimulated by peritoneal cDC2s compared to cDC1s, "Leukocyte_transendothelial_migration" and "Regulation_of_actin_cytoskeleton". (J) Heatmap of the genes involved in CD8 T cell status.
\end{abstract}

T cells. Stimulation with cDC1s was superior in activating OT-1 T cells. Also, cDC1s promoted the lung-homing capacity of OT-1 T cells while cDC2s increased the expression of gut-homing molecules on the surface. Like all other tissues, the peritoneal cavity contains a much smaller number of $\mathrm{CDC} 1 \mathrm{~s}$ than that of cDC2s within the whole cDC population. However, the phenotypic and functional outcomes of whole peritoneal cDCs were quite similar to those of peritoneal cDC1s. Global mRNAsequencing analysis of transcriptomes also confirmed that the overall gene expression profile of OT-1 T cells stimulated by whole $\mathrm{cDCs}$ were similar to those stimulated by $\mathrm{CDC} 1 \mathrm{~s}$ but not cDC2s. Therefore, our study demonstrates that peritoneal $\mathrm{cDC} 1 \mathrm{~s}$ play a dominant role over other $\mathrm{cDCs}$ in controlling the responses of $\mathrm{CD}^{+}$OT- 1 T cells.

The cytokine milieu is important for the differentiation of $\mathrm{T}$ cells. It is shown that TCR-stimulated T cells and bystander T cells are differentially influenced and polarized in the culture containing IL-2 (45). Recent studies on the cytokine milieus that lead the differentiation of $\mathrm{T}$ cells into specific subsets indicated that DCs actively take part in generating such conditions. DCs can directly secrete certain cytokines and/or modulate the response to specific cytokines $(22,23)$. DCs can also indirectly regulate the level of particular cytokines by inducing $\mathrm{T}$ cells to secrete and/or to consume those cytokines $(21,22)$. Besides, CD25 on Ag-presenting DCs can participate in transpresentation of IL-2 to Ag-responding T cells $(14,46)$. Meanwhile, IL-2 immunotherapy is found to expand and activate the population of DCs, and thus boost immunity (47). Our present study illustrated that peritoneal $\mathrm{cDC} 1 \mathrm{~s}$, but not cDC2s, are able to promote OT-1 T cells to secrete a high level of IL-2. Although the increased level of IL-2 modulates the gene expression profile of OT-1 T cells stimulated by $\mathrm{cDC} 2 \mathrm{~s}$ to mimic that of OT-1 T cells stimulated by $\mathrm{CDC} 1 \mathrm{~s}$, a significant number of genes are still regulated by cDC2s independently of IL-2. In fact, IL-2 is a complicated cytokine producing different outcomes depending on the type, strength, and duration of signals $(14,48)$. For example, a strong IL-2 signal, in combination with inflammatory cytokines, induces the expression of transcription factor T-bet and Blimp-1, which in turn promotes the differentiation of short-lived effector CD8 T cells (20). On the other hand, weak IL-2 signals are involved in the formation of memory T cells $(18,19)$. Thus, we cannot exclude the possibility that DEGs between the stimulations with $\mathrm{cDC} 1 \mathrm{~s}$ and CDC2s with IL-2 may be due to the inadequate dose and/or the prolonged duration of IL-2 signals. In addition, other modulating factors derived from cDC1s may act on $\mathrm{T}$ cells synergistically and/or cooperatively with IL-2, which requires further studies.

We also discovered that peritoneal $\mathrm{cDC} 1 \mathrm{~s}$ and whole $\mathrm{cDCs}$ induce OT-1 T cells to up-regulate CCR4, a chemokine receptor for lung and inflamed tissues $(41,42)$, and to down-regulate $\alpha 4 \beta 7$ and CCR9, homing molecules for gut tissues $(49,50)$, in an IL-2 dependent manner. On the other hand, peritoneal $\mathrm{cDC} 2 \mathrm{~s}$ induce OT-1 T cells to express a variety of chemokine receptors and integrins, homing molecules for various tissues, as well as CD62L, a homing receptor for lymphoid tissues. Consistent with this observation, in competitive adoptive transfer assays, most of the OT-1 T cells activated by $\mathrm{cDC} 1 \mathrm{~s}$ migrate into the lung, whereas those stimulated by $\mathrm{cDC} 2 \mathrm{~s}$ migrate into various lymphoid tissues as well as the lung. In the meantime, T cells activated by $\mathrm{cDC} 2 \mathrm{~s}$ with IL-2 show the homing properties of $\mathrm{T}$ cells induced by both peritoneal cDC1s and CDC2s. They downregulate gut-homing molecules but up-regulate both CCR4 and various other chemokine receptors expressed by OT-1 T cells stimulated by cDC2s. Accordingly, their homing properties are not limited to the lung but also able to migrate into various lymphoid tissues. Notably, despite the augmented expression of gut-homing molecules, OT-1 T cells stimulated by $\mathrm{cDC} 2 \mathrm{~s}$ are unable to migrate into gut tissues in competitive adoptive transfer assays. Besides these findings, no significant guthoming properties of OT-1 T cells are observed following adoptive transfer into the recipient mice treated with OVA and IL-2 (data not shown).

The mechanisms of how different peritoneal $\mathrm{cDC}$ subsets lead to the different outcomes of $\mathrm{CD}^{+} \mathrm{T}$ cell responses are not fully recognized in vivo. It is notable that, although the expression of TGF- $\beta$ in OT- 1 T cells is not influenced by the stimulation with different peritoneal cDC subsets, TGF- $\beta$ is expressed higher in peritoneal $c D C 2 s$ than in $c D C 1 s$. Since TGF- $\beta$ mediates complex effects on the immune system by dampening or promoting $\mathrm{T}$ cell responses as well as regulating the expression of integrins and CD69 $(35,38,51)$, the different expression of TGF- $\beta$ between 
A

$$
\text { OT-1 T cultured with peritoneal CDCs }
$$
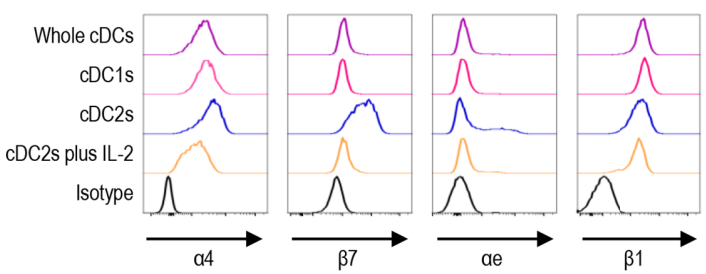

C

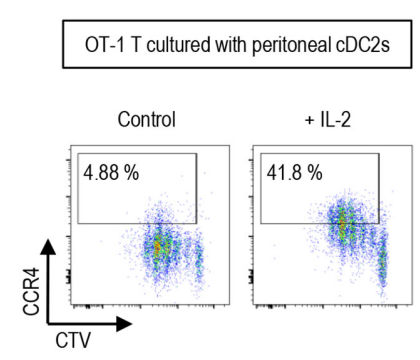

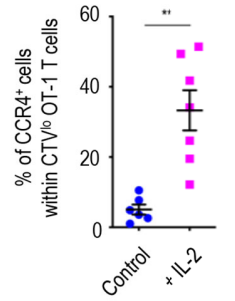

B

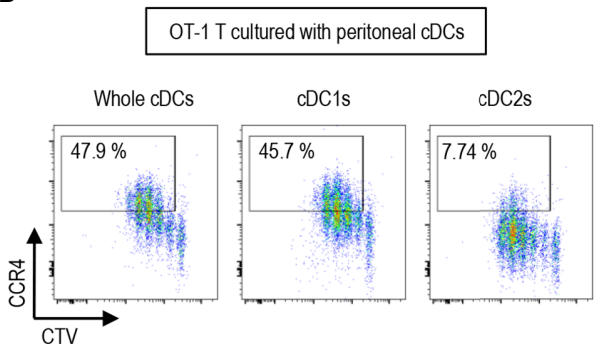

D

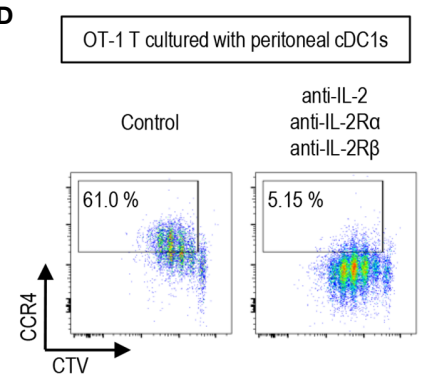

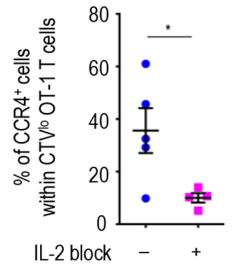

E

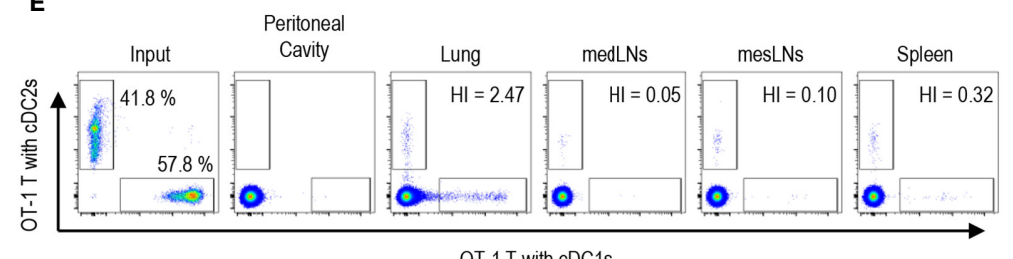

OT-1 T with $\mathrm{CDC} 1 \mathrm{~s}$

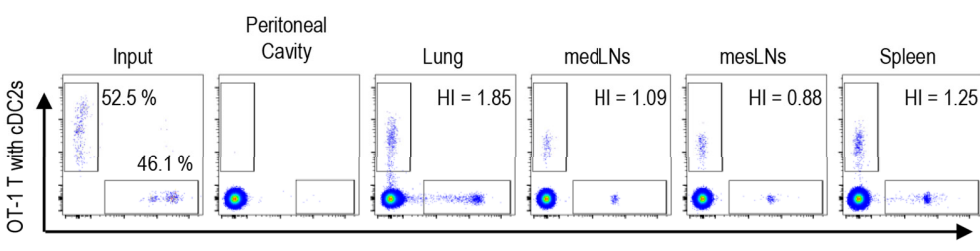

OT-1 T with cDC2s plus IL-2

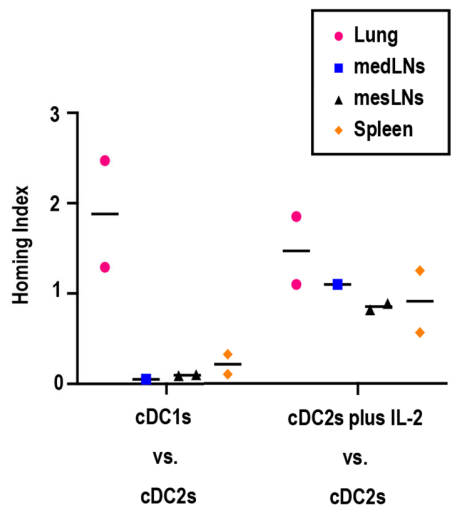

FIGURE 5 | Peritoneal cDCs induce CD8 T cells with distinct homing properties. $1.5 \mathrm{mg}$ of OVA (Grade V) was injected into the peritoneal cavity for an hour. OVA-laden peritoneal CDC subsets were isolated and co-cultured with naïv OT- 1 T cells for 3 days before analysis. (A) OT-1 T cells stimulated by cDCs were stained for integrins $\alpha 4, \beta 7, \alpha e$, and $\beta 1$ (representative of more than 3 independent experiments). (B) Surface expression of CCR4 in OT-1 T cells stimulated by peritoneal cDCs are shown (representative of 4 independent experiments). (C) Effect of IL-2 on CCR4 expression. OT-1 T cells and peritoneal CDC2s were co-cultured with or without $100 \mathrm{ng} / \mathrm{ml}$ of IL-2 for 3 days. Live CTV ${ }^{\circ} \mathrm{CD} 8^{+} \mathrm{T}$ cells are plotted and the percentages of cells expressing CCR4 among CTV ${ }^{\circ}$ proliferated OT-1 T cells are shown in a graph. Data are pooled from 2 independent experiments $(n \geq 6)$. Error bars indicate mean \pm SEM. (D) Expression of CCR4 on OT-1 T cells stimulated by peritoneal CDC1s while blocking IL-2 signaling. OT-1 T cells and peritoneal cDC1s were cocultured with antibodies blocking IL-2 signaling ( $2 \mu \mathrm{g} / \mathrm{ml}$ of polyclonal anti-IL-2, $10 \mu \mathrm{g} / \mathrm{ml}$ of PC61 anti-IL-2R $\alpha$, and $10 \mu \mathrm{g} / \mathrm{ml}$ of TmB1 anti-IL-2Rß) for 3 days. Live CTV ${ }^{\circ}$ CD8 $8^{+}$T cells are plotted and the percentages of cells expressing CCR4 among CTV ${ }^{\circ}$ proliferated OT-1 T cells are shown in a graph. Data are pooled from 2 independent experiments $(n \geq 4)$. Error bars indicate mean \pm SEM. (E) Homing index (HI) measured by competitive adoptive transfer experiments. OT-1 T cells were stimulated by cDC2s (labeled with CFSE), cDC1s (labeled with CTV), or CDC2s plus IL-2 (labeled with CTV). Labeled OT-1 T cells were mixed 1:1 and adoptively transferred intravenously (i.v.) into recipient mice. A total of 500,000 cells containing an equal mixture of OT-1 T cells respectively stimulated by CDC1s vs. cDC2s (upper panels) or a total of 1,000,000 cells containing an equal mixture of OT-1 T cells respectively stimulated by CDC2s plus IL-2 vs. cDC2s (lower panels) were adoptively transferred. After 3 hours of competitive adoptive transfer, HI of each tissue was determined. $\mathrm{HI}$ was calculated as $\left[\mathrm{CTV}^{+} / \mathrm{CFSE}^{+}\right]_{\text {issue }}\left[\mathrm{CTV}^{+} / \mathrm{CFSE}^{+}\right]_{\text {input }}$. Graph shows means of $2 \mathrm{HI}$ values from 2 independent experiments. ${ }^{*} \mathrm{p}<0.05$; ${ }^{* *} \mathrm{p}<0.01$.

peritoneal $\mathrm{cDC}$ subsets might also be involved in controlling the differential expression of genes in $\mathrm{CD}^{+} \mathrm{T}$ cells. Interestingly, the dominant feature of $\mathrm{cDC} 1 \mathrm{~s}$ on controlling the responses of $\mathrm{Ag}$ responding $\mathrm{CD}^{+} \mathrm{T}$ cells is only observed when a small amount of LPS is co-delivered i.p. with the Ag, indicating that peritoneal cDC1s are better at activating OT-1 T cells, in part, because they are more sensitive to LPS. Although the expression of TLR4 gene in both peritoneal $\mathrm{cDC} 1 \mathrm{~s}$ and $\mathrm{CDC} 2 \mathrm{~s}$ is similar, the signaling 
molecules are expressed differently. Also, the higher expression and induction of $\mathrm{CD} 86$ on peritoneal $\mathrm{CDC} 1 \mathrm{~s}$ are notable, while other co-stimulatory molecules are expressed higher on peritoneal cDC2s with/without LPS treatment. Meanwhile, peritoneal cDC subsets did not induce distinct CD8 T cell responses nor showed dominance over each other when $\mathrm{Ag}$ and LPS was co-delivered in vitro (data not shown). This likely suggests that, to acquire the dominant feature, $\mathrm{CDC} 1 \mathrm{~s}$ need maturation stimuli directly as well as indirectly from the in vivo treatment of LPS. It will be important to elucidate the nature of stimulating signals inside the peritoneal cavity that maturate $\mathrm{cDC} 1 \mathrm{~s}$ and the underlying mechanisms of how different $\mathrm{cDC}$ subsets lead to distinct $\mathrm{T}$ cell responses.

\section{DATA AVAILABILITY STATEMENT}

The datasets presented in this study can be found in online repositories. The names of the repository/repositories and accession number(s) can be found in the article/Supplementary Material.

\section{ETHICS STATEMENT}

The animal study was reviewed and approved by Institutional Animal Care and Use Committees of the Yonsei University College of Medicine.

\section{AUTHOR CONTRIBUTIONS}

Conceptualization: CP. Methodology: MS, HN, and CP. Formal analysis, MS and HN. Investigation: MS, HN, HS, SR, SP, HI, WC, JP, and SH. Writing - original draft: MS, HN, and CP.

\section{REFERENCES}

1. Steinman RM. Decisions About Dendritic Cells: Past, Present, and Future. Annu Rev Immunol (2012) 30:1-22. doi: 10.1146/annurev-immunol-100311-102839

2. Steinman RM, Witmer MD. Lymphoid Dendritic Cells are Potent Stimulators of the Primary Mixed Leukocyte Reaction in Mice. Proc Natl Acad Sci USA (1978) 75(10):5132-6. doi: 10.1073/pnas.75.10.5132

3. Merad M, Sathe P, Helft J, Miller J, Mortha A. The Dendritic Cell Lineage: Ontogeny and Function of Dendritic Cells and Their Subsets in the Steady State and the Inflamed Setting. Annu Rev Immunol (2013) 31:563-604. doi: 10.1146/annurev-immunol-020711-074950

4. Bosteels C, Neyt K, Vanheerswynghels M, van Helden MJ, Sichien D, Debeuf $\mathrm{N}$, et al. Inflammatory Type $2 \mathrm{Cdcs}$ Acquire Features of $\mathrm{cDC} 1 \mathrm{~s}$ and Macrophages to Orchestrate Immunity to Respiratory Virus Infection. Immunity (2020) 52(6):1039-56.e9. doi: 10.1016/j.immuni.2020.04.005

5. Clausen BE, Stoitzner P. Functional Specialization of Skin Dendritic Cell Subsets in Regulating T Cell Responses. Front Immunol (2015) 6:534. doi: 10.3389/fimmu.2015.00534

6. Guilliams M, Dutertre CA, Scott CL, McGovern N, Sichien D, Chakarov S, et al. Unsupervised High-Dimensional Analysis Aligns Dendritic Cells Across Tissues and Species. Immunity (2016) 45(3):669-84. doi: 10.1016/j.immuni.2016.08.015

7. Johansson-Lindbom B, Svensson M, Pabst O, Palmqvist C, Marquez G, Forster R, et al. Functional Specialization of Gut CD103+ Dendritic Cells in
Writing - review \& editing: MS and CP. Visualization: MS and HN. Supervision: CP. Project administration: MS and HN. Funding acquisition: HN, MC, and CP. All authors contributed to the article and approved the submitted version.

\section{FUNDING}

We were supported by grants from the National Research Foundation of Korea to CP (2017M3A9C8064887, 2019R1F1A1041700), HYN (2017R1A6A3A11028388), and MC (2019R1F1A1053841), the "Dongwha" Faculty Research Assistance Program of the Yonsei University College of Medicine to CP (6-2020-0111), and the Brain Korea 21 PLUS/FOUR Project for Medical Science, Yonsei University.

\section{ACKNOWLEDGMENTS}

We would like to thank Min Kyung Kwon and the Flow Cytometry Core of the Yonsei Biomedical Research Institute for assistance with sorting and flow cytometry analyses, HoKeun Kwon and Kichun Kim for help with experiments, Bitna Lee for support with sequencing data analysis, and the Department of Laboratory Animal Resources of the Yonsei University College of Medicine for assistance with animals.

\section{SUPPLEMENTARY MATERIAL}

The Supplementary Material for this article can be found online at: https://www.frontiersin.org/articles/10.3389/fimmu.2021. 648348/full\#supplementary-material the Regulation of Tissue-Selective T Cell Homing. J Exp Med (2005) 202 (8):1063-73. doi: 10.1084/jem.20051100

8. Kim TG, Kim SH, Park J, Choi W, Sohn M, Na HY, et al. Skin-Specific CD301b(+) Dermal Dendritic Cells Drive Il-17-Mediated Psoriasis-Like Immune Response in Mice. J Invest Dermatol (2018) 138(4):844-53. doi: 10.1016/j.jid.2017.11.003

9. Mansouri S, Katikaneni DS, Gogoi H, Pipkin M, Machuca TN, Emtiazjoo AM, et al. Lung IFNAR1(hi) Tnfr2(+) cDC2 Promotes Lung Regulatory T Cells Induction and Maintains Lung Mucosal Tolerance At Steady State. Mucosal Immunol (2020) 13(4):595-608. doi: 10.1038/s41385-020-0254-1

10. Varol C, Vallon-Eberhard A, Elinav E, Aychek T, Shapira Y, Luche H, et al. Intestinal Lamina Propria Dendritic Cell Subsets Have Different Origin and Functions. Immunity (2009) 31(3):502-12. doi: 10.1016/j.immuni.2009.06.025

11. Miller JC, Brown BD, Shay T, Gautier EL, Jojic V, Cohain A, et al. Deciphering the Transcriptional Network of the Dendritic Cell Lineage. Nat Immunol (2012) 13(9):888-99. doi: 10.1038/ni.2370

12. Sichien D, Lambrecht BN, Guilliams M, Scott CL. Development of Conventional Dendritic Cells: From Common Bone Marrow Progenitors to Multiple Subsets in Peripheral Tissues. Mucosal Immunol (2017) 10(4):831-44. doi: 10.1038/mi.2017.8

13. Mildner A, Jung S. Development and Function of Dendritic Cell Subsets. Immunity (2014) 40(5):642-56. doi: 10.1016/j.immuni.2014.04.016

14. Boyman O, Sprent J. The Role of Interleukin-2 During Homeostasis and Activation of the Immune System. Nat Rev Immunol (2012) 12(3):180-90. doi: 10.1038/nri3156 
15. Fontenot JD, Rasmussen JP, Gavin MA, Rudensky AY. A Function for Interleukin 2 in Foxp3-expressing Regulatory T Cells. Nat Immunol (2005) 6(11):1142-51. doi: 10.1038/ni1263

16. Kallies A, Xin A, Belz GT, Nutt SL. Blimp-1 Transcription Factor is Required for the Differentiation of Effector CD8(+) T Cells and Memory Responses. Immunity (2009) 31(2):283-95. doi: 10.1016/j.immuni.2009.06.021

17. Setoguchi R, Hori S, Takahashi T, Sakaguchi S. Homeostatic Maintenance of Natural Foxp3(+) Cd25(+) CD4(+) Regulatory T Cells by Interleukin (IL)-2 and Induction of Autoimmune Disease by IL-2 Neutralization. J Exp Med (2005) 201(5):723-35. doi: 10.1084/jem.20041982

18. Feau S, Arens R, Togher S, Schoenberger SP. Autocrine IL-2 is Required for Secondary Population Expansion of CD8(+) Memory T Cells. Nat Immunol (2011) 12(9):908-13. doi: 10.1038/ni.2079

19. Williams MA, Tyznik AJ, Bevan MJ. Interleukin-2 Signals During Priming are Required for Secondary Expansion of CD8+ Memory T Cells. Nature (2006) 441(7095):890-3. doi: 10.1038/nature04790

20. Xin A, Masson F, Liao Y, Preston S, Guan T, Gloury R, et al. A Molecular Threshold for Effector CD8(+) T Cell Differentiation Controlled by Transcription Factors Blimp-1 and T-Bet. Nat Immunol (2016) 17(4):422-32. doi: 10.1038/ni.3410

21. Sela U, Park CG, Park A, Olds P, Wang S, Steinman RM, et al. Dendritic Cells Induce a Subpopulation of IL-12Rbeta2-Expressing Treg That Specifically Consumes IL-12 to Control Th1 Responses. PloS One (2016) 11(1):e0146412. doi: 10.1371/journal.pone.0146412

22. Soares H, Waechter H, Glaichenhaus N, Mougneau E, Yagita H, Mizenina O, et al. A Subset of Dendritic Cells Induces CD4+ T Cells to Produce IFNgamma by an IL-12-independent But CD70-dependent Mechanism In Vivo. J Exp Med (2007) 204(5):1095-106. doi: 10.1084/jem.20070176

23. Kawabe T, Yi J, Kawajiri A, Hilligan K, Fang D, Ishii N, et al. Requirements for the Differentiation of Innate T-bet(high) Memory-Phenotype CD4(+) T Lymphocytes Under Steady State. Nat Commun (2020) 11(1):3366. doi: 10.1038/s41467-020-17136-1

24. Ghosn EE, Cassado AA, Govoni GR, Fukuhara T, Yang Y, Monack DM, et al. Two Physically, Functionally, and Developmentally Distinct Peritoneal Macrophage Subsets. Proc Natl Acad Sci USA (2010) 107(6):2568-73. doi: 10.1073/pnas.0915000107

25. Bain CC, Hawley CA, Garner H, Scott CL, Schridde A, Steers NJ, et al. LongLived Self-Renewing Bone Marrow-Derived Macrophages Displace EmbryoDerived Cells to Inhabit Adult Serous Cavities. Nat Commun (2016) 7: ncomms11852. doi: 10.1038/ncomms11852

26. Kim KW, Williams JW, Wang YT, Ivanov S, Gilfillan S, Colonna M, et al. Mhc II+ Resident Peritoneal and Pleural Macrophages Rely on IRF4 for Development From Circulating Monocytes. J Exp Med (2016) 213(10):1951-9. doi: 10.1084/jem.20160486

27. Sohn M, Na HY, Ryu SH, Choi W, In H, Shin HS, et al. Two Distinct Subsets Are Identified From the Peritoneal Myeloid Mononuclear Cells Expressing Both CD11c and CD115. Immune Netw (2019) 19(3):e15. doi: 10.4110/in.2019.19.e15

28. Ryu SH, Na HY, Sohn M, Choi W, In H, Shin HS, et al. Competent AntigenPresenting Cells are Generated From the Long-Term Culture of Splenocytes With Granulocyte-Macrophage Colony-Stimulating Factor. Immunol Lett (2017) 188:96-107. doi: 10.1016/j.imlet.2017.06.010

29. Shin HS, Chun HR, Na HY, Sohn M, Ryu SH, Choi W, et al. Distinct Effects of Different Adjuvants in the Mouse Model of Allergic Airway Inflammation. Asian Pac J Allergy Immunol (2020). doi: 10.12932/AP-301219-0729

30. Ruane D, Chorny A, Lee H, Faith J, Pandey G, Shan M, et al. Microbiota Regulate the Ability of Lung Dendritic Cells to Induce IgA Class-Switch Recombination and Generate Protective Gastrointestinal Immune Responses. J Exp Med (2016) 213(1):53-73. doi: 10.1084/jem.20150567

31. Ryu SH, Na HY, Sohn M, Han SM, Choi W, In H, et al. Reduced Expression of Granule Proteins During Extended Survival of Eosinophils in Splenocyte Culture With GM-CSF. Immunol Lett (2016) 173:7-20. doi: 10.1016/j.imlet.2016.03.003

32. Mikhak Z, Strassner JP, Luster AD. Lung Dendritic Cells Imprint T Cell Lung Homing and Promote Lung Immunity Through the Chemokine Receptor CCR4. J Exp Med (2013) 210(9):1855-69. doi: 10.1084/jem.20130091

33. Mac Sharry J, Shalaby KH, Marchica C, Farahnak S, Chieh-Li T, Lapthorne S, et al. Concomitant Exposure to Ovalbumin and Endotoxin Augments Airway Inflammation But Not Airway Hyperresponsiveness in a Murine Model of Asthma. PloS One (2014) 9(6):e98648. doi: 10.1371/journal.pone.0098648

34. Mauffray M, Domingues O, Hentges F, Zimmer J, Hanau D, Michel T. Neurturin Influences Inflammatory Responses and Airway Remodeling in Different Mouse
Asthma Models. J Immunol (2015) 194(4):1423-33. doi: 10.4049/ jimmunol.1402496

35. Zhang N, Bevan MJ. Transforming Growth Factor-Beta Signaling Controls the Formation and Maintenance of Gut-Resident Memory $\mathrm{T}$ Cells by Regulating Migration and Retention. Immunity (2013) 39(4):687-96. doi: 10.1016/j.immuni.2013.08.019

36. Boyman O, Kovar M, Rubinstein MP, Surh CD, Sprent J. Selective Stimulation of T Cell Subsets With Antibody-Cytokine Immune Complexes. Science (2006) 311(5769):1924-7. doi: 10.1126/science.1122927

37. Iwata M, Hirakiyama A, Eshima Y, Kagechika H, Kato C, Song SY. Retinoic Acid Imprints Gut-Homing Specificity on T Cells. Immunity (2004) 21 (4):527-38. doi: 10.1016/j.immuni.2004.08.011

38. Konkel JE, Chen W. Balancing Acts: The Role of TGF-beta in the Mucosal Immune System. Trends Mol Med (2011) 17(11):668-76. doi: 10.1016/j.molmed.2011.07.002

39. Singer M, Wang C, Cong L, Marjanovic ND, Kowalczyk MS, Zhang H, et al. A Distinct Gene Module for Dysfunction Uncoupled From Activation in TumorInfiltrating T Cells. Cell (2016) 166(6):1500-11.e9. doi: 10.1016/j.cell.2016.08.052

40. Lamb CA, O’Byrne S, Keir ME, Butcher EC. Gut-Selective Integrin-Targeted Therapies for Inflammatory Bowel Disease. J Crohns Colitis (2018) 12 (suppl_2):S653-68. doi: 10.1093/ecco-jcc/jjy060

41. Brinkman CC, Peske JD, Engelhard VH. Peripheral Tissue Homing Receptor Control of Naive, Effector, and Memory CD8 T Cell Localization in Lymphoid and nonLymphoid Tissues. Front Immunol (2013) 4:241. doi: 10.3389/fimmu.2013.00241

42. Griffith JW, Sokol CL, Luster AD. Chemokines and Chemokine Receptors: Positioning Cells for Host Defense and Immunity. Annu Rev Immunol (2014) 32:659-702. doi: 10.1146/annurev-immunol-032713-120145

43. Baaten BJ, Cooper AM, Swain SL, Bradley LM. Location, Location, Location: The Impact of Migratory Heterogeneity on T Cell Function. Front Immunol (2013) 4:311. doi: 10.3389/fimmu.2013.00311

44. Helft J, Bottcher J, Chakravarty P, Zelenay S, Huotari J, Schraml BU, et al. Gm-Csf Mouse Bone Marrow Cultures Comprise a Heterogeneous Population of CD11c(+)MHCII(+) Macrophages and Dendritic Cells. Immunity (2015) 42(6):1197-211. doi: 10.1016/j.immuni.2015.05.018

45. Cho JH, Kim HO, Kim KS, Yang DH, Surh CD, Sprent J. Unique Features of Naive CD8+ T Cell Activation by IL-2. J Immunol (2013) 191(11):5559-73. doi: 10.4049/jimmunol.1302293

46. Wuest SC, Edwan JH, Martin JF, Han S, Perry JS, Cartagena CM, et al. A Role for Interleukin-2 Trans-Presentation in Dendritic Cell-Mediated T Cell Activation in Humans, as Revealed by Daclizumab Therapy. Nat Med (2011) 17(5):604-9. doi: 10.1038/nm.2365

47. Raeber ME, Rosalia RA, Schmid D, Karakus U, Boyman O. Interleukin-2 Signals Converge in a Lymphoid-Dendritic Cell Pathway That Promotes Anticancer Immunity. Sci Transl Med (2020) 12(561):eaba5464. doi: 10.1126/scitranslmed.aba5464

48. Liao W, Lin JX, Leonard WJ. Interleukin-2 At the Crossroads of Effector Responses, Tolerance, and Immunotherapy. Immunity (2013) 38(1):13-25. doi: 10.1016/j.immuni.2013.01.004

49. Mora JR, Bono MR, Manjunath N, Weninger W, Cavanagh LL, Rosemblatt M, et al. Selective Imprinting of Gut-Homing T Cells by Peyer's Patch Dendritic Cells. Nature (2003) 424(6944):88-93. doi: 10.1038/nature01726

50. Villablanca EJ, Cassani B, von Andrian UH, Mora JR. Blocking Lymphocyte Localization to the Gastrointestinal Mucosa as a Therapeutic Strategy for Inflammatory Bowel Diseases. Gastroenterology (2011) 140(6):1776-84. doi: 10.1053/j.gastro.2011.02.015

51. Travis MA, Sheppard D. Tgf- $\beta$ Activation and Function in Immunity. Annu Rev Immunol (2014) 32:51-82. doi: 10.1146/annurev-immunol-032713-120257

Conflict of Interest: CP is employed by GENUV Inc.

The remaining authors declare that the research was conducted in the absence of any commercial or financial relationships that could be construed as a potential conflict of interest.

Copyright (C) 2021 Sohn, Na, Shin, Ryu, Park, In, Choi, Park, Hwang, Chu and Park. This is an open-access article distributed under the terms of the Creative Commons Attribution License (CC BY). The use, distribution or reproduction in other forums is permitted, provided the original author(s) and the copyright owner(s) are credited and that the original publication in this journal is cited, in accordance with accepted academic practice. No use, distribution or reproduction is permitted which does not comply with these terms. 